\title{
A radiological survey of two bruker D8 advance XRD instruments located in separate quality control laboratories
}

Justin Anthony Meador

Follow this and additional works at: https://researchrepository.wvu.edu/etd

\section{Recommended Citation}

Meador, Justin Anthony, "A radiological survey of two bruker D8 advance XRD instruments located in separate quality control laboratories" (2016). Graduate Theses, Dissertations, and Problem Reports. 4010. https://researchrepository.wvu.edu/etd/4010

This Problem/Project Report is protected by copyright and/or related rights. It has been brought to you by the The Research Repository @WVU with permission from the rights-holder(s). You are free to use this Problem/Project Report in any way that is permitted by the copyright and related rights legislation that applies to your use. For other uses you must obtain permission from the rights-holder(s) directly, unless additional rights are indicated by a Creative Commons license in the record and/ or on the work itself. This Problem/Project Report has been accepted for inclusion in WVU Graduate Theses, Dissertations, and Problem Reports collection by an authorized administrator of The Research Repository @ WVU. For more information, please contact researchrepository@mail.wvu.edu. 
A Radiological Survey of Two Bruker D8 Advance XRD Instruments Located in Separate Quality Control Laboratories

\author{
by \\ Justin Meador \\ Problem Report submitted to the \\ Benjamin M. Statler College of Engineering and Mineral Resources \\ at West Virginia University \\ in partial fulfillment of the requirements \\ for the degree of \\ Master of Science
in
Industrial Hygiene \\ Dr. Steven Guffey, Ph.D., CIH, Chair \\ Dr. Gary Winn, Ph.D. \\ Shaun Larsen MPH, CIH, CSP
}

Industrial and Management Systems Engineering

Morgantown, West Virginia

2016

Keywords: radiological, survey, Bruker

Copyright 2016 Justin Meador 


\section{ABSTRACT \\ A Radiological Survey of Two Bruker D8 Advance XRD Instruments Located in Separate Quality Control Laboratories}

\section{By Justin Meador}

In October 2016, XYZ Laboratories requested assistance with conducting a radiological survey of each of their Bruker D8 Advance XRD instruments to determine compliance with Title 64 West Virginia Legislative Rule, Department of Health, Series 23, Radiological Health Rules (64CSR23) and 10 CFR Part 20 - Standards for Protection Against Radiation in regards to the X-Ray radiation being emitted during operation of the units.

A review of ionizing radiation, sources of radiation, biological effects, unit descriptions, Federal and State standards, description of the Bruker units, and a meta-analysis were conducted in preparation and in conclusion of the survey. A thorough survey was conducted for both units, and results were communicated using tables, graphs, and statistical analysis.

Data analysis showed a statistically significant difference between data observed in 2014 and 2015 for both labs when compared to the data from the 2016 survey, with the 2016 data showing higher measurements. Three possible explanations of the higher 2016 data were presented as follows: The first is the power setting for which the Bruker unit is being used has never been documented and could not be confirmed for consistency. The second is related to the recent replacement of the ceramic x-ray tubes. The third could be a result of the detector type that was used for the 2016 data since it was different than the one used in previous years

According to the survey results, both laboratories were near or below the background measurements with only one survey point above the background for each lab. In addition, the exposure summaries demonstrate that Lab A and Lab B are well below the $0.05 \mathrm{~Sv} / \mathrm{yr}$ established by both the State and Federal standards, with measurements of 8.82E-05 Sv/yr and 1.12E-04 Sv/yr, respectively.

It is recommended to continue with the current established procedures. This includes continuing the current Preventative Maintenance Program as well as replacing parts as needed. It should be noted that a survey must be conducted any time a replacement part is installed on the unit.

According to both standards identified in this report, personal dosimetry is not needed due to the low measurements. If at any time a survey results in an above acceptable level, additional testing must be conducted and personal dosimetry considered.

The final recommendation is to continue with the annual survey schedule conducted by or under the supervision of a Certified Health Physicist. A request should be submitted to record the locations and values associated with all survey points. With this more historical data can be obtained to see how levels fluctuate and where the strongest emissions occur. The power levels should be noted and kept consistent with each survey. In addition, a Scintillator detector should be used in future surveys to more accurately measure the lower level gamma radiation. 


\section{List of Figures}

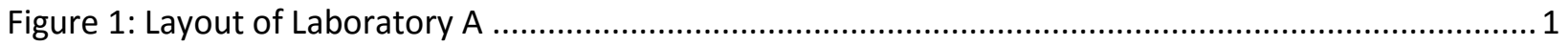

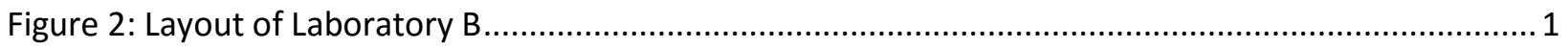

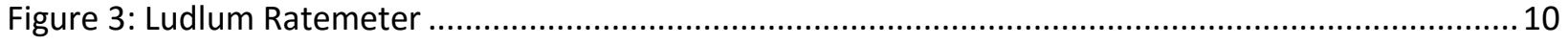

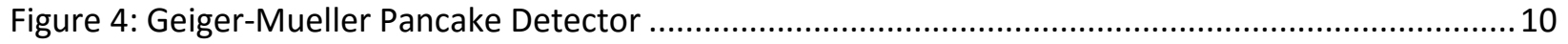

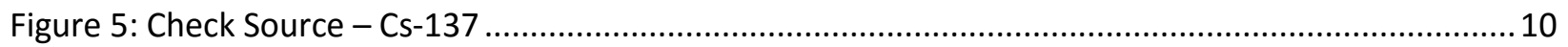

Figure 6: 2016 Lab A Room Layout and Site Survey Points............................................................. 14

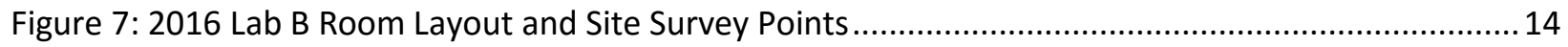

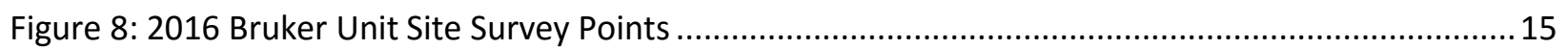

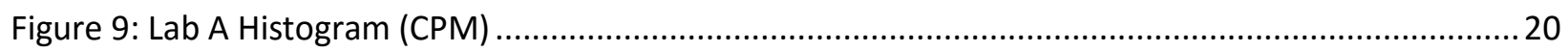

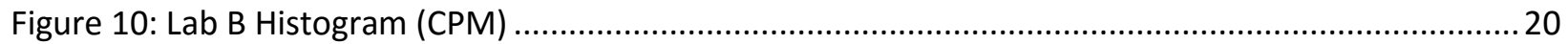

Figure 11: Box Plot of Two Sample T-test comparing Lab A and Lab B (CPM) .........................................21

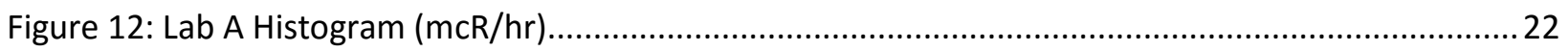

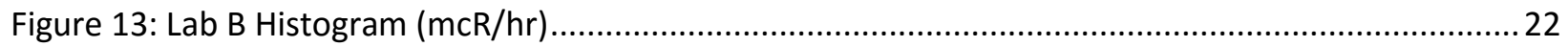

Figure 14: Box Plot of Two Sample T-test comparing Lab A and Lab B (mcR/hr) .................................23

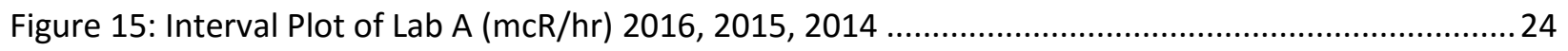

Figure 16: Normal Probability Plot Lab A (mcR/hr) 2016, 2015, 2014.................................................24

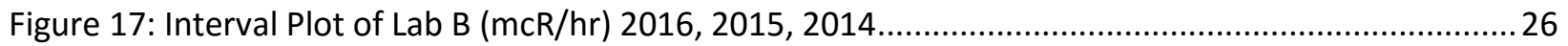

Figure 18: Normal Probability Plot Lab B (mcR/hr) 2016, 2015, 2014...............................................26 


\section{List of Tables}

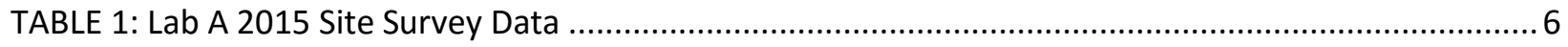

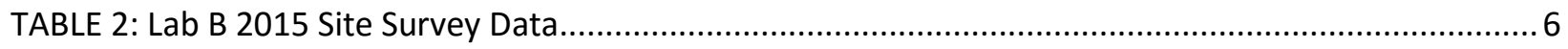

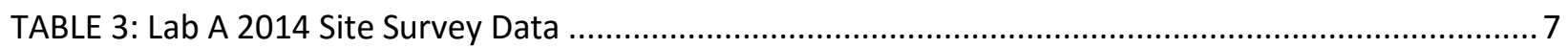

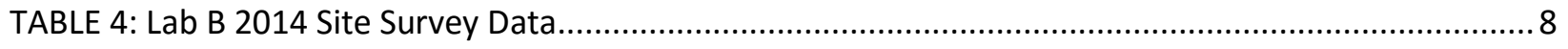

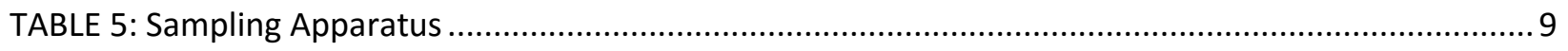

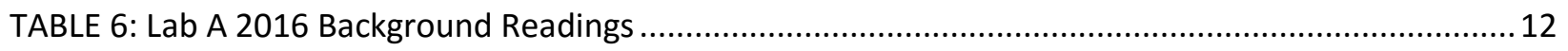

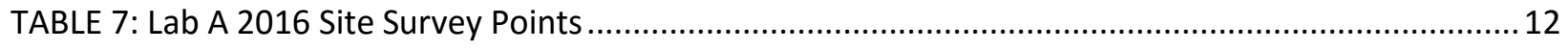

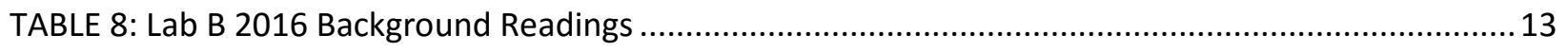

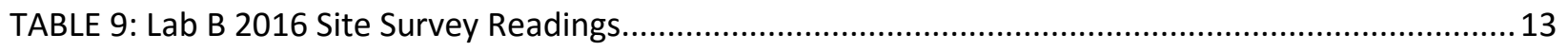

TABLE 10: Lab A 2016 Reference Check Results (Cs-137 S/N 871) .......................................................17

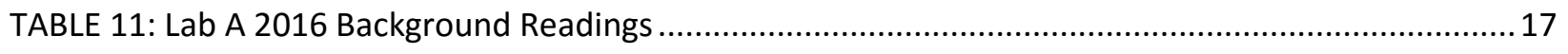

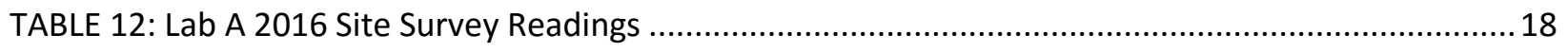

TABLE 13: Lab B 2016 Reference Check Results (Cs-137 S/N 871) .....................................................19

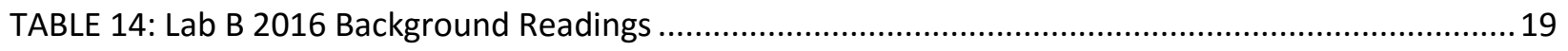

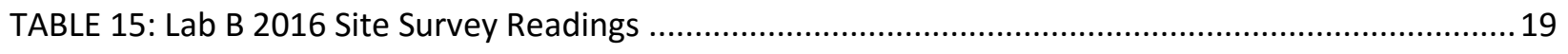

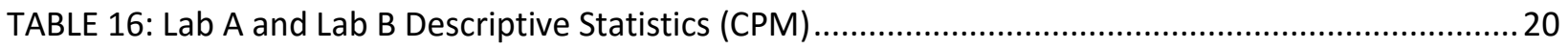

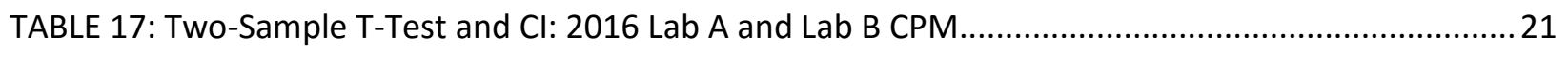

TABLE 18: Lab A and Lab B Descriptive Statistics (mcR/hr) ...............................................................2

TABLE 19: Two-Sample T-Test and Cl: 2016 Lab A and Lab B mcR/hr, ...............................................23

TABLE 20: One-Way ANOVA Lab A (mcR/hr) 2016, 2015, 2014 Statistical Summary .............................25

TABLE 21: One-Way ANOVA Lab B (mcR/hr) 2016, 2015, 2014 Statistical Summary...............................27

Table 22: Lab A Annual Dose Exposure Summary ......................................................................28

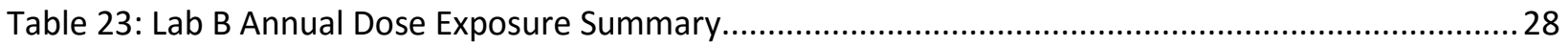




\section{Table of Contents}

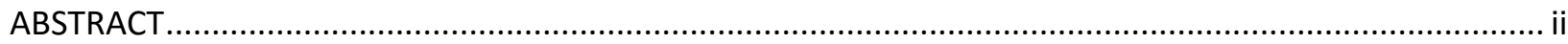

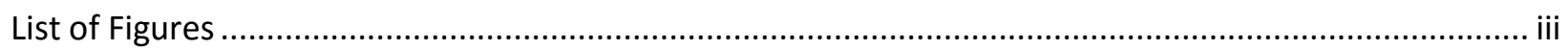

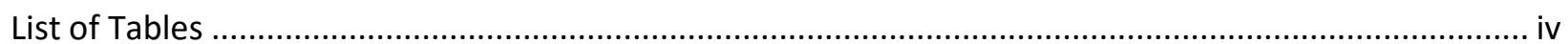

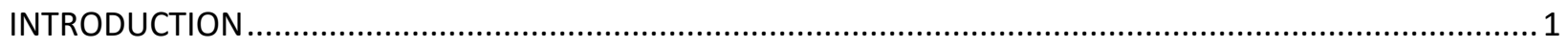

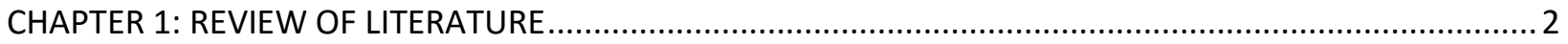

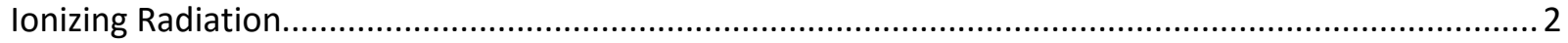

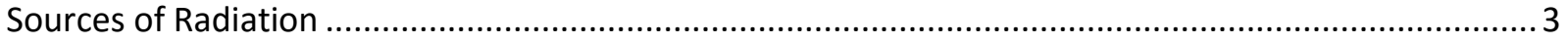

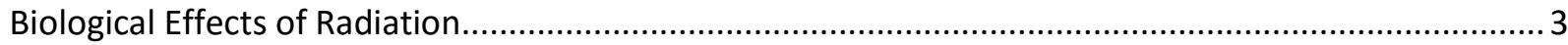

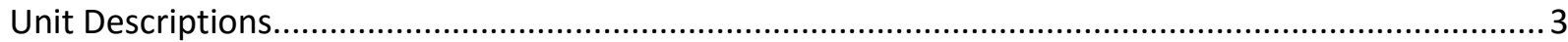

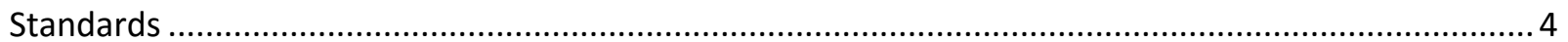

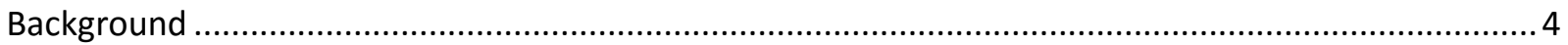

Description of Bruker D8 Advance XRD Instrument ......................................................

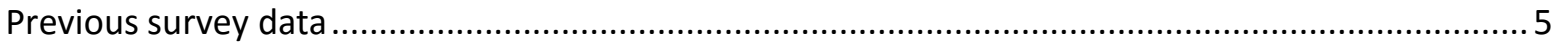

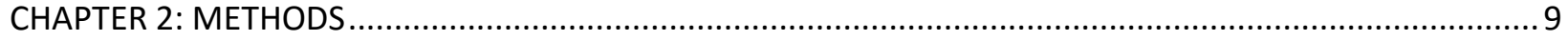

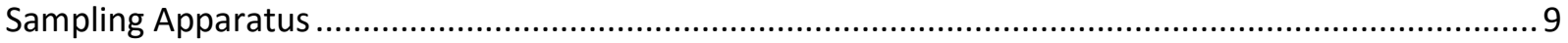

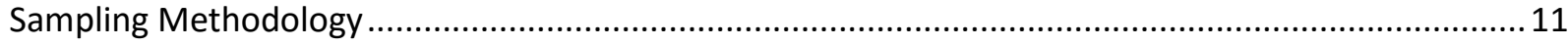

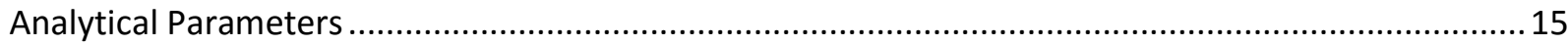

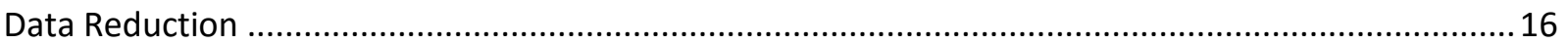

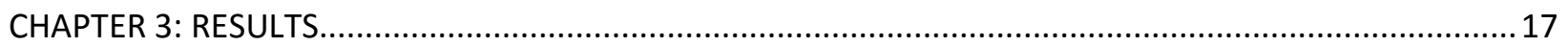

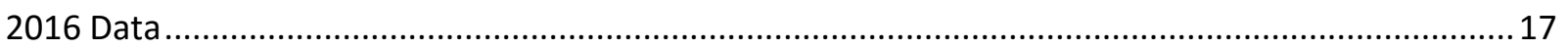

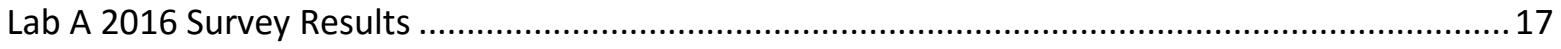

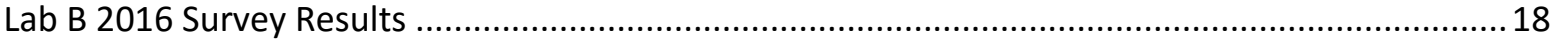

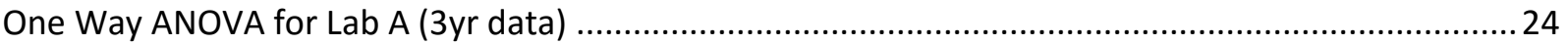

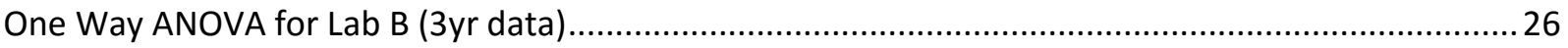

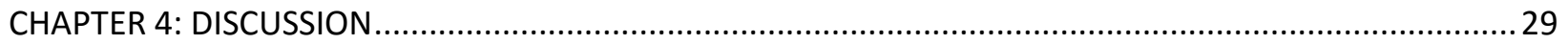

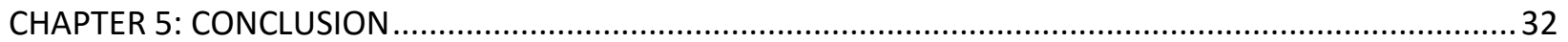

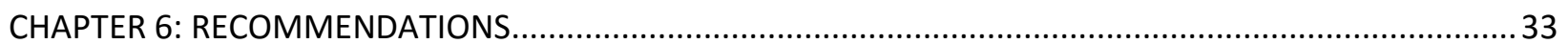

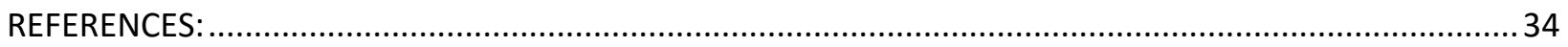

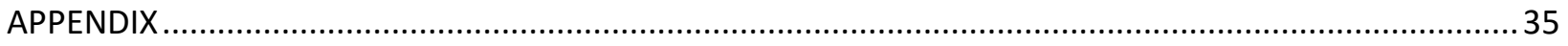

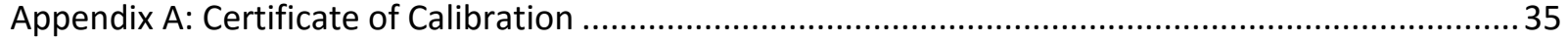




\section{INTRODUCTION}

In October 2016, XYZ Laboratories requested assistance with conducting a radiological survey of each of their Bruker D8 Advance XRD instruments located at 123 Radiation Drive Radville, ZZ 98765 (Lab A) and 321 Geiger Springs Radville, ZZ 98765 (Lab B). These surveys were conducted with the intent to determine compliance with State and Federal Standards in regards to the amount of X-Ray radiation being emitted during operation of the units. The Bruker unit location in each laboratory room is provided in Figures 1 and 2.

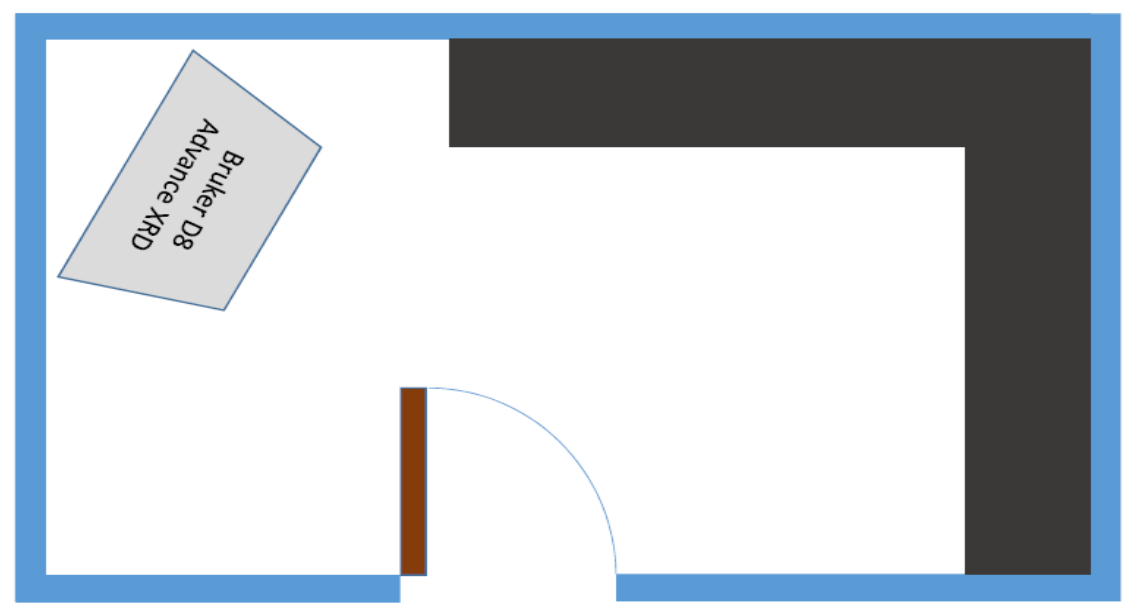

Figure 1: Layout of Laboratory A

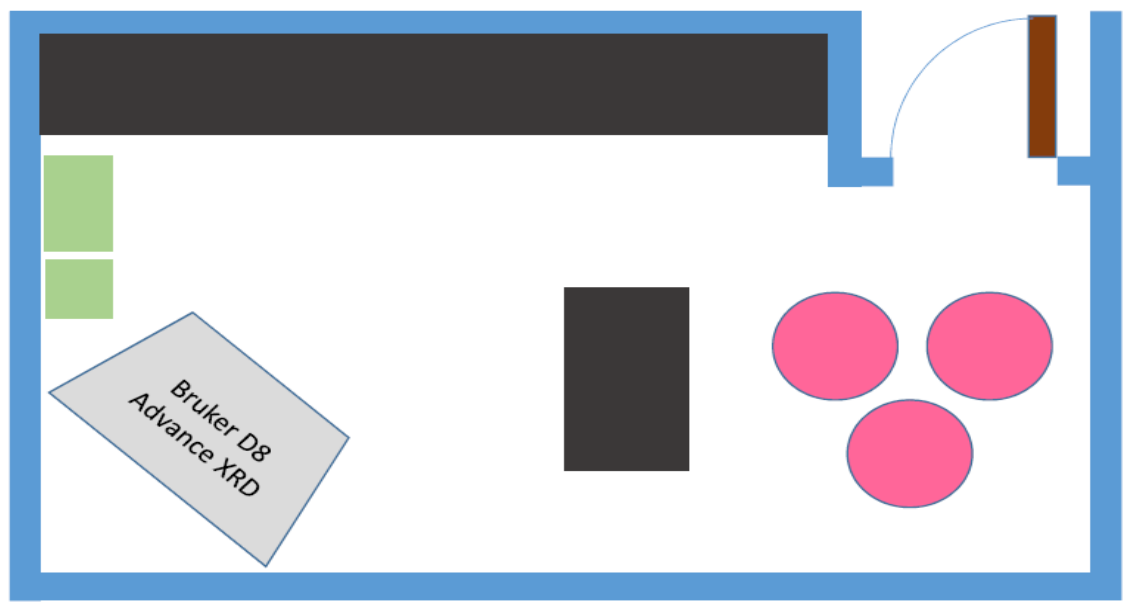

Figure 2: Layout of Laboratory $B$ 


\section{CHAPTER 1: REVIEW OF LITERATURE}

This review of literature discusses ionizing radiation, sources of radiation, biological effects of radiation, unit descriptions, standards, background information concerning the Bruker D8 Advance XRD Instrument and previous survey data.

\section{Ionizing Radiation}

Ionizing radiation can be defined as radiation that has the ability to create ions that interact with and alter biological structures. It is produced by unstable atoms, which are different from stable atoms due to their excess energy, mass, or both. Unstable atoms are radioactive. To become stable, these atoms release, or emit, their excess electrons and/or energy. These emissions are called radiation. Ionizing radiation can be found in the following types:

1) Alpha Radiation

Occurs when an atom undergoes radioactive decay. During this process, it releases a particle (called an alpha particle) changing the original atom to an isotope. Due to their charge and mass, alpha particles interact strongly with matter. Alpha particles are so weak that they cannot penetrate the outer layer of dead skin cells, but are capable of causing serious cell damage if ingested or inhaled. (Mirion, 2010; UMT, 2002)

2) Beta Radiation

Takes the form of an electron being emitted from an atom. It can travel further than an alpha particle but can be stopped by a thick piece of plastic or even a stack of paper. It can also penetrate skin by a few centimeters, posing a minor external health risk. Their primary threat is also from ingested material. (Mirion, 2010; UMT, 2002)

3) Gamma Radiation

Gamma radiation does not consist of particles and instead consists of a photon of energy being emitted from an unstable nucleus. Due to its higher energy and nearly zero mass, it can penetrate much farther than alpha or beta particles. It is emitted by naturally radioactive materials/occurrences, such as cosmic rays, lighting, and radioactive decay from elements such as radium. Gamma radiation can be stopped by a sufficient thickness of lead or depleted uranium. (Mirion, 2010; UMT, 2002) 
4) X-Rays

X-rays are similar to gamma radiation but are not naturally occurring. They are generated from the electron cloud of atoms, as opposed to the nucleus. In addition, X-Rays have longer-wavelengths and typically have lower energy than gamma radiation. (Mirion, 2010; UMT, 2002)

\section{Sources of Radiation}

Radiation can be emitted from many sources, both natural/background and man-made. Natural/background sources of radiation are all around us. They include cosmic rays from the sun, radiation from the ground and the earth itself (e.g., radon). As a result, the human body and building materials are naturally radioactive. Man-made sources of radiation can be found in sources such as medical devices, fallout from nuclear bombs, some consumer products, and from nuclear power plants.

\section{Biological Effects of Radiation}

When biological cells become exposed to radiation, several components of DNA and other proteins within the cell become ionized, resulting in charged particles that break existing bonds and form new bonds, causing the potential for DNA strands to break apart and proteins to become denatured by altering their physical structure from their naturally occurring form. This results in a loss of their three dimensional structure, which then in turn alters its function. Certain areas of the body and organs, such as the lymphoid organs, bone marrow, blood, testes, ovaries, and intestines are more susceptible to the effects of radiation, which is reflected in the varying allowable dose scheme produced by Occupational Safety and Health Administration and the International Atomic Energy Agency.

\section{Unit Descriptions}

Counts Per Minute (CPM) - a unit of measurement for a Geiger counter. It can be defined as the number of atoms in a given quantity of radioactive material that are detected to have decayed in one minute. (Ludlum, 2011)

$\underline{\text { Roentgen }(\mathrm{R})}$ - defined as "The amount of X- or gamma-radiation that produces ionization resulting in one electrostatic unit of charge in one cubic centimeter of dry air at standard conditions.” (Plog and Quinlan, 2002) 
$\underline{\text { Seivert }(\mathrm{Sv})}$ - defined as "Unit of absorbed radiation dose times the quality factor of the radiation as compared to gamma-radiation.” (Plog and Quinlan, 2002)

\section{Standards}

1) Title 64 West Virginia Legislative Rule, Department of Health, Series 23, Radiological Health Rules (64CSR23)

- The annual dose limit states "The total effective dose equivalent being equal to five onehundredths (0.05) Sv." (WVDHHR)

- The results of each survey will be compared to this standard in regards to annual allowable dose limits, as well as recommendations in terms of future surveys and monitoring.

2) 10 CFR Part 20 - Standards for Protection Against Radiation

- The annual dose limit states "The total effective dose equivalent being equal to five onehundredths (0.05) Sv." (U.S. NRC)

- The results of each survey will be compared to this standard in regards to annual allowable dose limits, as well as recommendations in terms of future surveys and monitoring.

\section{Background}

\section{Description of Bruker D8 Advance XRD Instrument}

For this study, a Bruker D8 Advance XRD instrument was utilized as a device to analyze a sample element to determine its composition by bombarding it with x-rays. This process is called "diffractometry" and is discussed below. In this particular application, the quality control lab uses the XRD to analyze powder samples from various products to determine phase identification of crystalline material, to obtain information on unit cell dimensions, and to test sample purity.

Each Bruker D8 Advance XRD instruments produces X-rays using a ceramic x-ray generating tube, with a $\mathrm{Cu}$ anode as the primary $\mathrm{x}$-ray beam source. In this design, $\mathrm{x}$-rays are generated when a focused electron beam accelerated across a high voltage field strikes a stationary solid $\mathrm{Cu}$ target. As electrons collide with atoms in the target and slow down, a continuous spectrum of $\mathrm{x}$ rays is emitted. The power is adjustable from $20-60 \mathrm{kV}$ (Bruker, 2009). According to the 
Bruker Technical Operations Manual, the amount of X-ray radiation emitted fluctuates linearly with changes in the power setting.

Each Bruker D8 Advance XRD unit uses a low energy, sealed X-ray source that is contained within a radiation-safe cabinet with all appropriate shielding and required multiple safety interlocks. For that reason, operation of this instrument does not require personnel dosimetry monitoring such as a film badge. Each Bruker unit undergoes annual maintenance and functional testing in accordance to the manufacturer's specifications as detailed in the Bruker Technical Operations Manual. For XYZ Laboratories, this was conducted by a certified technician from Bruker.

\section{Previous survey data}

The results from previous surveys are provided below. These surveys were utilized as a basic template for this project. The surveys were combined with current data to conduct a metaanalysis of data sets from 2014, 2015, and 2016.

\section{1) 2016 Consultant Surveys}

The 2016 consultant surveys were conducted on the same day as the surveys for this project. The same make and model equipment utilized by the consultant was rented for this project. However, the consultant did not provide data sets. They simply stated that all site survey points were at or below background measurements.

\section{2) 2015 Survey Data from Both Labs}

2015 survey data for both Labs A and B are listed in Tables 1 and 2, respectively. These tables communicate the site survey point identifications and descriptions, as well as their associated survey data. This data will be utilized for a meta-analysis to compare data from 2014, 2015, and 2016. It should be noted that both labs received an annual dose well below the $0.05 \mathrm{sV} / \mathrm{yr}$ listed in 64CSR23 and 10 CFR Part 20. Specifically, Lab A was calculated at 2.20E-05 Sv/yr and Lab B was found to be equal background readings at 2.20E-06 Sv/yr. 
TABLE 1: Lab A 2015 Site Survey Data

\begin{tabular}{|c|l|c|c|}
\hline Location ID & Description & $\mu \mathrm{R} / \mathrm{hr}$ & $\mu \mathrm{Sv} / \mathrm{hr}$ \\
\hline SP-1 & Work Station adjacent to D8 & 8.0 & 0.0848 \\
\hline SP-2 & Work Station, TGA Q5000 Operator & 8.0 & 0.0848 \\
\hline SP-3 & Top left edge of sash & 8.0 & 0.0848 \\
\hline SP-4 & Bottom left edge of sash & 7.0 & 0.0742 \\
\hline SP-5 & Bottom left of instrument & 7.0 & 0.0742 \\
\hline SP-6 & Top left center of sash & 7.0 & 0.0742 \\
\hline SP-7 & Bottom left center of sash & 6.8 & 0.0721 \\
\hline SP-8 & Bottom left center of instrument & 8.0 & 0.0848 \\
\hline SP-9 & Top center of sash & 6.0 & 0.0636 \\
\hline SP-10 & Bottom right center of sash & 7.0 & 0.0742 \\
\hline SP-11 & Bottom right center of instrument & 7.0 & 0.0742 \\
\hline SP-12 & Top right edge of sash & 7.0 & 0.0742 \\
\hline SP-13 & Bottom right edge of sash & 7.0 & 0.0742 \\
\hline SP-14 & Bottom right of instrument & 9.0 & 0.0954 \\
\hline SP-15 & Tile floor in front of D8 & & \\
\hline & & 7.0 & 0.0742 \\
\hline
\end{tabular}

TABLE 2: Lab B 2015 Site Survey Data

\begin{tabular}{|c|l|c|c|}
\hline Location ID & Description & $\mu \mathrm{R} / \mathrm{hr}$ & $\mu \mathrm{Sv} / \mathrm{hr}$ \\
\hline SP-1 & Work Station adjacent to D8 & 6.0 & 0.0636 \\
\hline SP-2 & Work Station near door & 6.0 & 0.0636 \\
\hline SP-3 & Work Station, D8 operator & 5.9 & 0.0625 \\
\hline SP-4 & Top left edge of sash & 4.5 & 0.0477 \\
\hline SP-5 & Bottom left edge of sash & 5.0 & 0.0530 \\
\hline SP-6 & Bottom left of instrument & 6.0 & 0.0636 \\
\hline SP-7 & Top left center of sash & 4.1 & 0.0435 \\
\hline SP-8 & Bottom left center of sash & 5.0 & 0.0530 \\
\hline SP-9 & Bottom left center of instrument & 6.0 & 0.0636 \\
\hline SP-10 & Top right center of sash & 4.0 & 0.0424 \\
\hline SP-11 & Bottom right center of sash & 6.0 & 0.0530 \\
\hline SP-12 & Bottom right center of instrument & 5.0 & 0.0636 \\
\hline SP-13 & Top right edge of sash & 4.5 & 0.0530 \\
\hline SP-14 & Bottom right edge of sash & 5.0 & 0.0477 \\
\hline SP-15 & Bottom right of instrument & 6.0 & 0.0636 \\
\hline SP-16 & Front of freeze dryer next to D8 & & \\
\hline
\end{tabular}




\section{3) 2014 Survey Data from Both Labs}

2014 survey data for both Labs A and B are listed in Tables 3 and 4, respectively. These tables communicate the site survey point identifications and descriptions, as well as their associated survey data. This data will be utilized for a meta-analysis to compare data from 2014, 2015, and 2016. It should be noted that both labs received an annual dose well below the $0.05 \mathrm{sV} / \mathrm{yr}$ listed in 64CSR23 and 10 CFR Part 20 with Lab A being calculated at 2.20E-05 Sv/yr and Lab B being equal to the background readings at 2.20E$06 \mathrm{~Sv} / \mathrm{yr}$.

TABLE 3: Lab A 2014 Site Survey Data

\begin{tabular}{|l|l|c|c|}
\hline Location ID & Description & $\mu \mathrm{R} / \mathrm{hr}$ & $\mu \mathrm{Sv} / \mathrm{hr}$ \\
\hline SP-1 & Work Station adjacent to D8 & 8.0 & 0.0848 \\
\hline SP-2 & Work Station, TGA Q5000 Operator & 7.0 & 0.0848 \\
\hline SP-3 & Top left edge of sash & 6.0 & 0.0848 \\
\hline SP-4 & Bottom left edge of sash & 7.0 & 0.0742 \\
\hline SP-5 & Bottom left of instrument & 8.0 & 0.0742 \\
\hline SP-6 & Top left center of sash & 7.0 & 0.0742 \\
\hline SP-7 & Bottom left center of sash & 7.0 & 0.0721 \\
\hline SP-8 & Bottom left center of instrument & 7.0 & 0.0848 \\
\hline SP-9 & Top center of sash & 7.0 & 0.0636 \\
\hline SP-10 & Bottom right center of sash & 7.0 & 0.0742 \\
\hline SP-11 & Bottom right center of instrument & 7.0 & 0.0742 \\
\hline SP-12 & Top right edge of sash & 7.0 & 0.0742 \\
\hline SP-13 & Bottom right edge of sash & 7.0 & 0.0742 \\
\hline SP-14 & Bottom right of instrument & 10.0 & 0.0954 \\
\hline SP-15 & Tile floor in front of D8 & & \\
\hline
\end{tabular}


TABLE 4: Lab B 2014 Site Survey Data

\begin{tabular}{|c|l|c|c|}
\hline Location ID & Description & $\mu \mathrm{R} / \mathrm{hr}$ & $\mu \mathrm{Sv} / \mathrm{hr}$ \\
\hline SP-1 & Work Station adjacent to D8 & 6.0 & 0.0636 \\
\hline SP-2 & Work Station near door & 5.0 & 0.0530 \\
\hline SP-3 & Work Station, D8 operator & 6.0 & 0.0636 \\
\hline SP-4 & Top left edge of sash & 5.0 & 0.0530 \\
\hline SP-5 & Bottom left edge of sash & 5.0 & 0.0530 \\
\hline SP-6 & Bottom left of instrument & 5.0 & 0.0530 \\
\hline SP-7 & Top left center of sash & 5.0 & 0.0530 \\
\hline SP-8 & Bottom left center of sash & 6.0 & 0.0636 \\
\hline SP-9 & Bottom left center of instrument & 5.0 & 0.0530 \\
\hline SP-10 & Top right center of sash & 5.0 & 0.0530 \\
\hline SP-11 & Bottom right center of sash & 5.0 & 0.0530 \\
\hline SP-12 & Bottom right center of instrument & 6.0 & 0.0636 \\
\hline SP-13 & Top right edge of sash & 5.0 & 0.0530 \\
\hline SP-14 & Bottom right edge of sash & 6.0 & 0.0636 \\
\hline SP-15 & Bottom right of instrument & 7.0 & 0.0742 \\
\hline SP-16 & Front of freeze dryer next to D8 & 6.0 & 0.0636 \\
\hline
\end{tabular}




\section{CHAPTER 2: METHODS}

This methods section discusses the sampling apparatus, sampling methodology, analytical parameters, and data reduction.

\section{Sampling Apparatus}

Ludlum Measurement, Inc. equipment was rented for this survey. This is the same equipment that was utilized in previous surveys, with the exception of the detector type. The consultant in 2016 used a Geiger-Mueller Pancake Detector, whereas the consultant in 2014 and 2015 used a sodium ion (NaI) gamma Scintillator Detector. The Pancake Detector was used for this project to stay consistent with the 2016 consultant. The equipment was calibrated by the Atlantic Nuclear Corporation on March $9^{\text {th }}, 2016$. A Certificate of Calibration has been provided in Appendix A. A list of the equipment, including the type, model \#, serial \#, and calibration date can be found in Table 5 .

TABLE 5: Sampling Apparatus

\begin{tabular}{|l|c|c|c|}
\hline \multicolumn{4}{|c|}{ Ludlum Measurements, Inc. } \\
\hline Equipment Type & Model \# & Serial \# & $\begin{array}{c}\text { Calibration } \\
\text { Date }\end{array}$ \\
\hline Ratemeter & $2241-2 R K$ & 296694 & $3 / 9 / 2016$ \\
\hline Geiger-Mueller Pancake Detector & $44-9$ & PR321985 & $3 / 9 / 2016$ \\
\hline Check Source (Cs-137) & N/A & 871 & N/A \\
\hline
\end{tabular}

*** Pictures of each of these are provided in Figures 3-5 


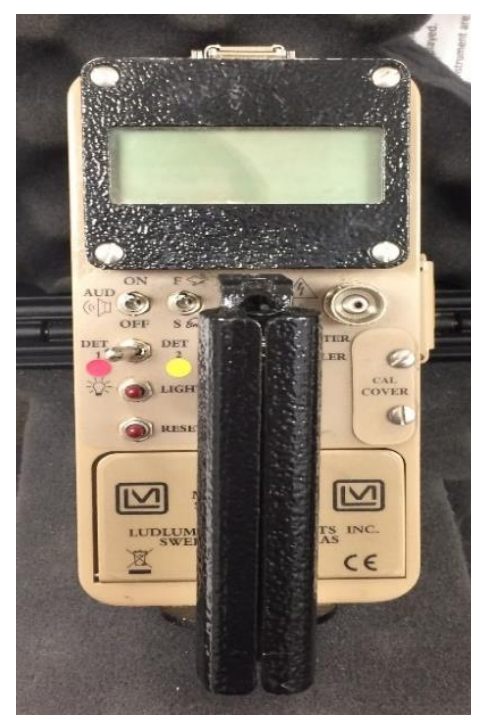

Figure 3: Ludlum Ratemeter

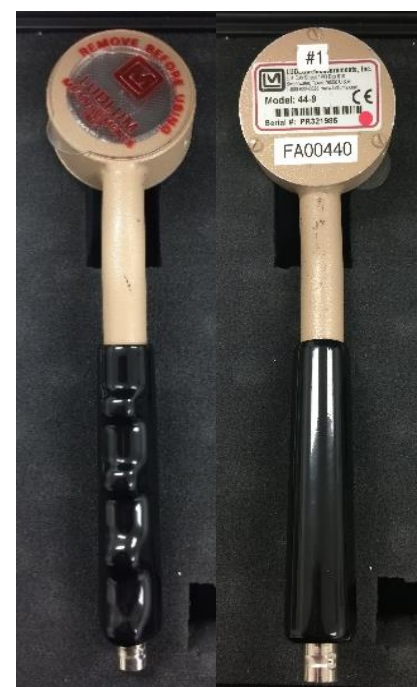

Figure 4: Geiger-Mueller Pancake Detector

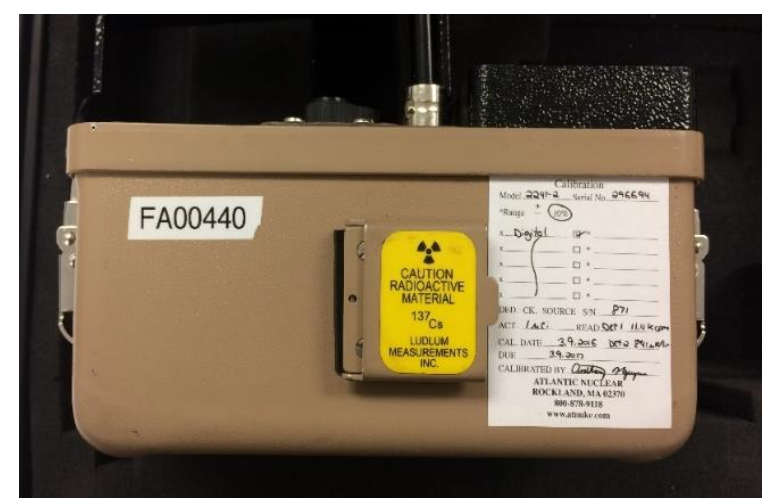

Figure 5: Check Source - Cs-137 


\section{Sampling Methodology}

On October $21^{\text {st }} 2016$, a radiological survey of two Bruker D8 Advance XRD instruments (See Figures 1 and 2) located in separate locations ( $\mathrm{Lab} \mathrm{A}$ and Lab B) was conducted in an effort to evaluate the amount of X-Ray radiation being emitted by the instruments to determine if the equipment's shielding provided the required energy attenuation.

A Ludlum Ratemeter (See Figure 3) and Geiger-Mueller Pancake Detector (See Figure 4) were utilized in obtaining the survey measurements. The digital Ratemeter is microprocessor-based equipment used to measure ionizing radiation. The display units can be represented in CPM's, R's, and Sv's with multipliers of micro and milli. It is equipped with independent adjustable alarm indicators and is capable of using a Geiger-Mueller Pancake Detector of a Sodium Ion Gamma Scintillator Detector. The Geiger-Mueller Pancake Detector is capable of detecting alpha, beta, and gamma radiation with a nominally linear response from $1 \mathrm{mR} / \mathrm{hr}$ to $300 \mathrm{mR} / \mathrm{hr}$.

The equipment was calibrated by the Atlantic Nuclear Corporation on March $9^{\text {th }}, 2016$ (See Appendix A). A pre/post reference check was conducted prior to surveying each instrument using a Cs-137 check source (See Figure 5) with a +/- 10\% range. Cs-137 is a reference to a radioactive isotope of Cesium which is used as the standard element for the calibration of radiation detection equipment.

The Bruker unit in each lab, as well as the room in which it is located, was subjected to two Background Measurements (BM) and 23 Site Survey Points (SP). The BMs and SPs are listed in Tables 6-9. A room layout with associated Survey Points, as well as a picture of each unit with associated Survey Points can be found in Figures 6-8. 
TABLE 6: Lab A 2016 Background Readings

\begin{tabular}{|c|l|}
\hline Location ID & Description \\
\hline BM-1 & Lab Counter outside of room \\
\hline BM-2 & Tile floor in front of lab counter \\
\hline
\end{tabular}

TABLE 7: Lab A 2016 Site Survey Points

\begin{tabular}{|l|l|}
\hline Location ID & Description \\
\hline SP-1 & Work Station adjacent to D8 \\
\hline SP-2 & Work Station, TGA Q5000 Operator \\
\hline SP-3 & Top left edge of sash \\
\hline SP-4 & Bottom left edge of sash \\
\hline SP-5 & Bottom left of instrument \\
\hline SP-6 & Top left center of sash \\
\hline SP-7 & Bottom left center of sash \\
\hline SP-8 & Bottom left center of instrument \\
\hline SP-9 & Top center of sash \\
\hline SP-10 & Middle center of sash \\
\hline SP-11 & Bottom center of sash \\
\hline SP-12 & Bottom center of instrument \\
\hline SP-13 & Middle left sash panel \\
\hline SP-14 & Middle left center sash panel \\
\hline SP-15 & Middle right center sash panel \\
\hline SP-16 & Middle right sash panel \\
\hline SP-17 & Top right center of sash \\
\hline SP-18 & Bottom right center of sash \\
\hline SP-19 & Bottom right center of instrument \\
\hline SP-20 & Top right edge of sash \\
\hline SP-22 & Bottom right edge of sash \\
\hline SP-23 & Tile floor in front of D8 \\
\hline
\end{tabular}


TABLE 8: Lab B 2016 Background Readings

\begin{tabular}{|c|l|}
\hline Location ID & Description \\
\hline BM-1 & Hallway outside room \\
\hline BM-2 & Tile floor outside room \\
\hline
\end{tabular}

TABLE 9: Lab B 2016 Site Survey Readings

\begin{tabular}{|l|l|}
\hline Location ID & Description \\
\hline SP-1 & Work Station adjacent to D8 \\
\hline SP-2 & Work Station, D8 operator \\
\hline SP-3 & Top left edge of sash \\
\hline SP-4 & Bottom left edge of sash \\
\hline SP-5 & Bottom left of instrument \\
\hline SP-6 & Top left center of sash \\
\hline SP-7 & Bottom left center of sash \\
\hline SP-8 & Bottom left center of instrument \\
\hline SP-9 & Top center of sash \\
\hline SP-10 & Middle center of sash \\
\hline SP-11 & Bottom center of sash \\
\hline SP-12 & Bottom center of instrument \\
\hline SP-13 & Middle left sash panel \\
\hline SP-14 & Middle left center sash panel \\
\hline SP-15 & Middle right center sash panel \\
\hline SP-16 & Middle right sash panel \\
\hline SP-17 & Top right center of sash \\
\hline SP-18 & Bottom right center of sash \\
\hline SP-19 & Bottom right center of instrument \\
\hline SP-23 & Top right edge of sash \\
\hline & Bottom right edge of sash \\
\hline Br-22 & Bottom right of instrument \\
\hline
\end{tabular}




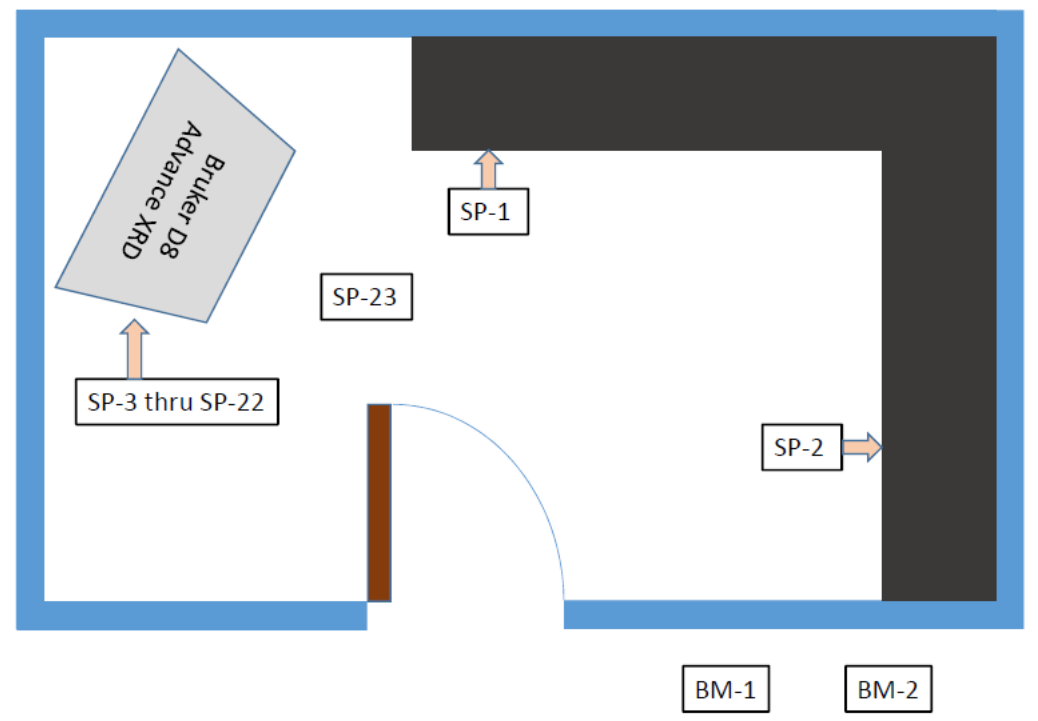

Figure 6: 2016 Lab A Room Layout and Site Survey Points

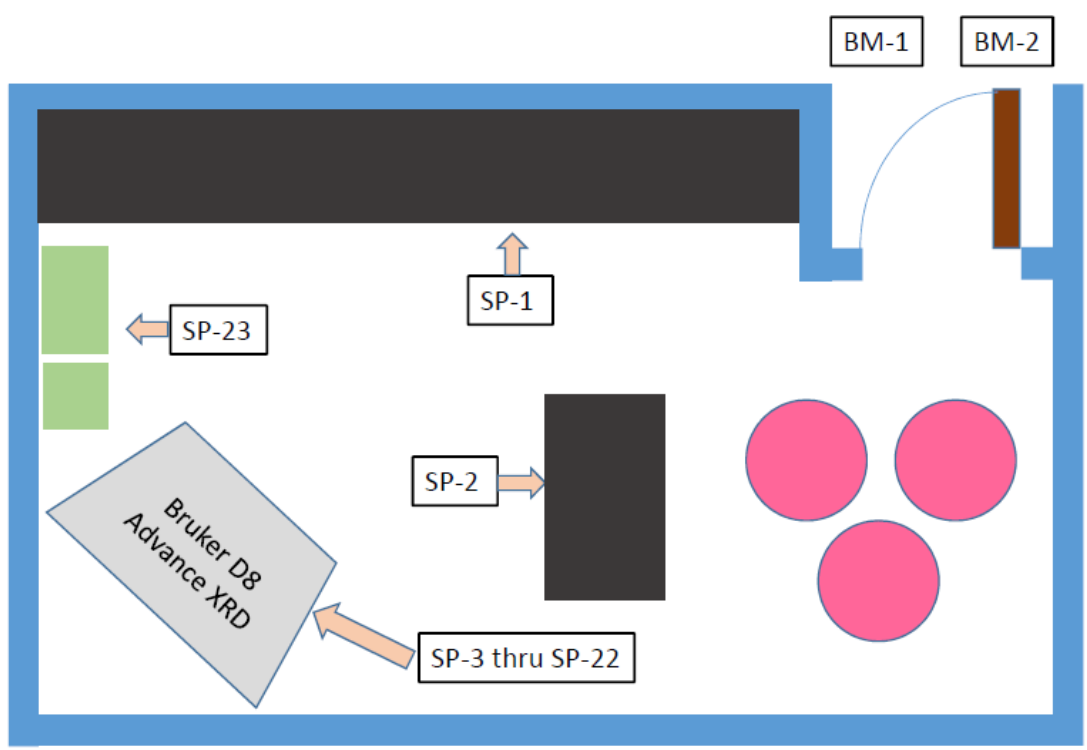

Figure 7: 2016 Lab B Room Layout and Site Survey Points 


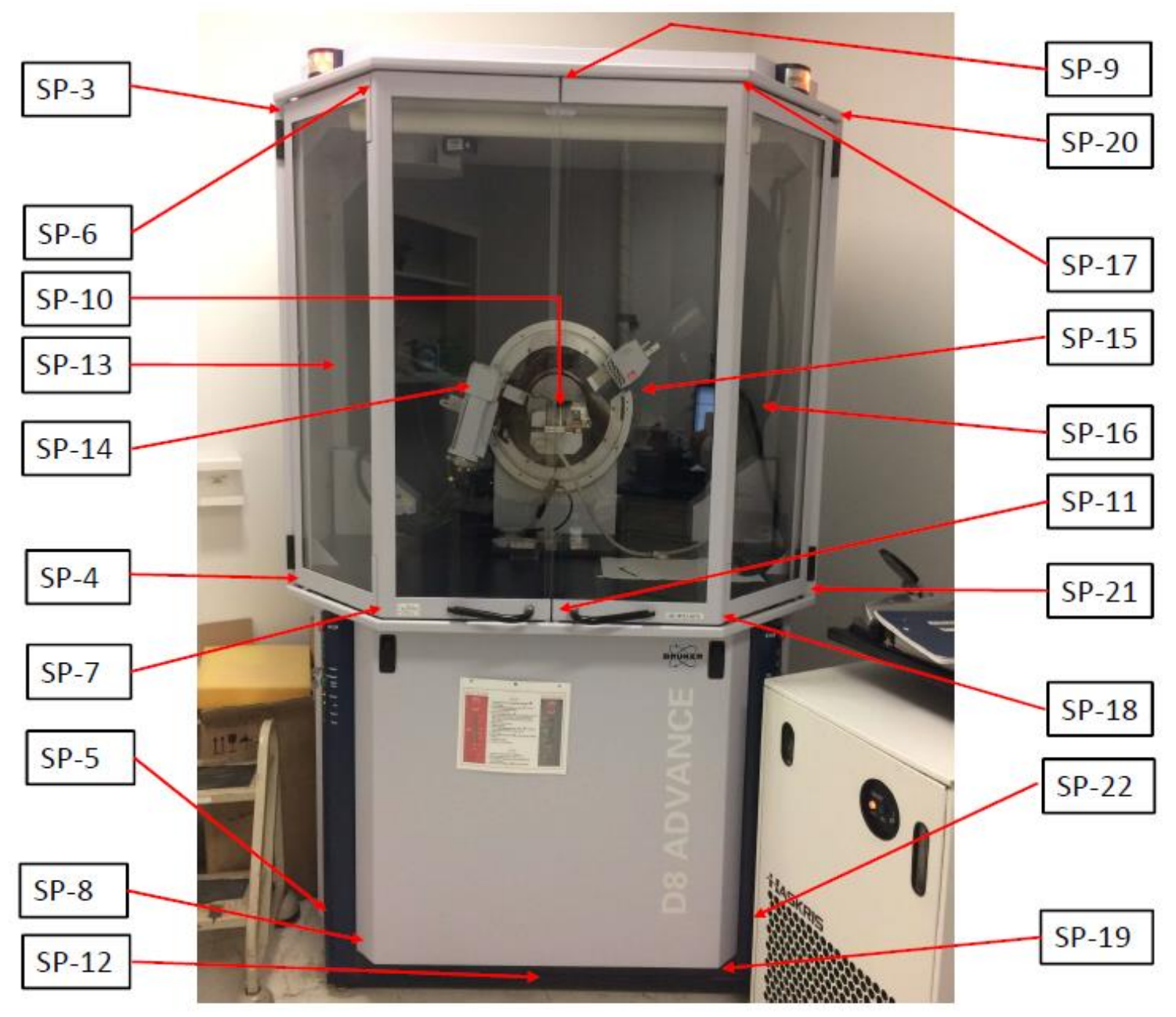

Figure 8: 2016 Bruker Unit Site Survey Points

\section{Analytical Parameters}

The Ludlum equipment provides instant, real-time results measured in CPM. This measurement data was converted into $\mu \mathrm{R} / \mathrm{hr}$ and $\mu \mathrm{SV} / \mathrm{hr}$ using conversion measures provided in the Ludlum Model 2241-2RK Response Kit Technical Manual (Ludlum, 2011). The conversions utilized for this survey include the following: $3300 \mathrm{CPM}=\mathrm{mR} / \mathrm{hr}, 1 \mu \mathrm{R} / \mathrm{hr}=0.0106 \mu \mathrm{Sv} / \mathrm{hr}$, and $1 \mathrm{SV}=$ $1,000,000 \mu \mathrm{Sv}$. 


\section{Data Reduction}

Data was organized and communicated using Tables 10-21 and communicated using Figures 918, as well as statistical methods. Microsoft ${ }^{\circledR}$ Excel ${ }^{\circledR}$ was utilized for the creation of tables and Minitab® 17 was utilized for the creation of graphs and statistical data. Bases on the 2106 site survey data, the annual dose limit was calculated using Microsoft $®$ Excel® and was then compared to Title 64 West Virginia Legislative Rule, Department of Health, Series 23, Radiological Health Rules (64CSR23) and 10 CFR Part 20 - Standards for Protection Against Radiation. Additionally, a sample was rejected if the pre and post-calibration differed by more than $5 \%$.

An exposure summary was computed for each Lab using an equation provided by the Ludlum Model 2241-2RK Response Kit Technical Manual. The difference between the highest Site Survey Point ( $\mu \mathrm{R} / \mathrm{hr})$ and the lowest Background Measurement $(\mu \mathrm{R} / \mathrm{hr})$ is used in this calculation to determine the yearly exposure level. It utilizes a 2080 -hour year ( $52 \mathrm{wks}$ at $40 \mathrm{hrs} / \mathrm{wk}$ ) for most employees working near the Bruker Unit. From this information, the following equation is used to calculate the annual dose exposure:

$$
\text { Annual dose exposure }=(2080-\mathrm{Y} \mu \mathrm{R} / \mathrm{yr}) *(0.0106 \mu \mathrm{Sv} / \mathrm{hr} / 1 \mu \mathrm{R} / \mathrm{hr})
$$

Where $\mathrm{Y}=$ Highest Site Survey Point - Lowest Background Measurement 


\section{CHAPTER 3: RESULTS}

Results found in this chapter are associated with the 2016 survey results for each lab organized into Tables 10-21, as well as graphical and statistical analysis of the data located in Figures 9-18. The use of the data will be described in each section.

\section{Data}

Tables 10-19 in this section are in reference to data collected through the 2016 surveys at Lab A and Lab B. Figures 9-14 are used to communicate the statistical results from the analysis of Labs $\mathrm{A}$ and $\mathrm{B}$. The use of the individual associated data will be described in each section.

\section{Lab A 2016 Survey Results}

Tables 10-12 communicate the results of the Lab A 2016 Reference Check Results, Background Readings, and Site Survey Points, respectively. Table 10 was used to determine whether or not a sample would be rejected. Table 11 was used in the calculation for the annual exposure. Table 12 was also used in the calculation for the annual exposure, but was also used for individual lab statistical analysis, as well as statistical analysis comparing 2016 Lab A and Lab B results and meta-analysis of Lab A historical data. Tables 16-19 are used to communicate the statistical results from the analysis of Labs A and B.

TABLE 10: Lab A 2016 Reference Check Results (Cs-137 S/N 871)

\begin{tabular}{|c|c|c|c|c|c|}
\hline Date & $\begin{array}{c}\text { Time } \\
\text { (AM) }\end{array}$ & $\begin{array}{c}\text { kCPM } \\
\text { (Target) }\end{array}$ & $\begin{array}{c}\text { kCPM } \\
\text { (Reading) }\end{array}$ & \% Accuracy & Pre/Post \% \\
\cline { 1 - 5 } $10 / 21 / 2016$ & $8: 27$ & 11.4 & 11.3 & $99 \%$ & \multirow{2}{*}{$4 \%$} \\
\hline $10 / 21 / 2016$ & $8: 42$ & 11.4 & 10.9 & $96 \%$ & \\
\hline
\end{tabular}

TABLE 11: Lab A 2016 Background Readings

\begin{tabular}{|c|l|c|c|c|}
\hline Location ID & Description & CPM & $\mu \mathrm{R} / \mathrm{hr}$ & $\mu \mathrm{Sv} / \mathrm{hr}$ \\
\hline BM-1 & Lab Counter outside of room & 70 & 21.2 & 0.2248 \\
\hline BM-2 & Tile floor in front of lab counter & 79 & 23.9 & 0.2538 \\
\hline
\end{tabular}


TABLE 12: Lab A 2016 Site Survey Readings

\begin{tabular}{|c|l|c|c|c|}
\hline Location ID & Description & CPM & $\mu \mathrm{R} / \mathrm{hr}$ & $\mu \mathrm{Sv} / \mathrm{hr}$ \\
\hline SP-1 & Work Station adjacent to D8 & 51 & 15.5 & 0.1638 \\
\hline SP-2 & $\begin{array}{l}\text { Work Station, TGA Q5000 } \\
\text { Operator }\end{array}$ & 38 & 11.5 & 0.1221 \\
\hline SP-3 & Top left edge of sash & 74 & 22.4 & 0.2377 \\
\hline SP-4 & Bottom left edge of sash & 43 & 13.0 & 0.1381 \\
\hline SP-5 & Bottom left of instrument & 41 & 12.4 & 0.1317 \\
\hline SP-6 & Top left center of sash & 61 & 18.5 & 0.1959 \\
\hline SP-7 & Bottom left center of sash & 35 & 10.6 & 0.1124 \\
\hline SP-8 & Bottom left center of instrument & 27 & 8.2 & 0.0867 \\
\hline SP-9 & Top center of sash & 65 & 19.7 & 0.2088 \\
\hline SP-10 & Middle center of sash & 67 & 20.3 & 0.2152 \\
\hline SP-11 & Bottom center of sash & 70 & 21.2 & 0.2248 \\
\hline SP-12 & Bottom center of instrument & 36 & 10.9 & 0.1156 \\
\hline SP-13 & Middle left sash panel & 70 & 21.2 & 0.2248 \\
\hline SP-14 & Middle left center sash panel & 83 & 25.2 & 0.2666 \\
\hline SP-15 & Middle right center sash panel & 47 & 14.2 & 0.1510 \\
\hline SP-16 & Middle right sash panel & 55 & 16.7 & 0.1767 \\
\hline SP-17 & Top right center of sash & 43 & 13.0 & 0.1381 \\
\hline SP-18 & Bottom right center of sash & 60 & 18.2 & 0.1927 \\
\hline SP-19 & Bottom right center of instrument & 36 & 10.9 & 0.1156 \\
\hline SP-20 & Top right edge of sash & 54 & 16.4 & 0.1735 \\
\hline SP-21 & Bottom right edge of sash & 52 & 15.8 & 0.1670 \\
\hline SP-22 & Bottom right of instrument & 34 & 10.3 & 0.1092 \\
\hline SP-23 & Tile floor in front of D8 & 75 & 22.7 & 0.2409 \\
\hline
\end{tabular}

\section{Lab B 2016 Survey Results}

Tables 13-15 communicate the results of the Lab B 2016 Reference Check Results, Background Readings, and Site Survey Points, respectively. Table 13 was used to determine whether or not a sample would be rejected. Table 14 was used in the calculation for the annual exposure. Table 15 was also used in the calculation for the annual exposure, but was also used for individual lab statistical analysis, as well as statistical analysis comparing 2016 Lab A and Lab B results and meta-analysis of Lab B historical data. Tables 16-19 are used to communicate the statistical results from the analysis of Labs A and B 
TABLE 13: Lab B 2016 Reference Check Results (Cs-137 S/N 871)

\begin{tabular}{|c|c|c|c|c|c|}
\hline Date & $\begin{array}{c}\text { Time } \\
\text { (AM) }\end{array}$ & $\begin{array}{c}\text { kCPM } \\
\text { (Target) }\end{array}$ & $\begin{array}{c}\text { kCPM } \\
\text { (Reading) }\end{array}$ & $\begin{array}{c}\% \\
\text { Accuracy }\end{array}$ & Pre/Post \% \\
\hline $10 / 21 / 2016$ & $9: 19$ & 11.4 & 10.9 & $96 \%$ & \multirow{2}{*}{$2 \%$} \\
\hline $10 / 21 / 2016$ & $9: 35$ & 11.4 & 11.1 & $97 \%$ & \\
\hline
\end{tabular}

TABLE 14: Lab B 2016 Background Readings

\begin{tabular}{|c|l|c|c|c|}
\hline Location ID & Description & CPM & $\mu \mathrm{R} / \mathrm{hr}$ & $\mu \mathrm{Sv} / \mathrm{hr}$ \\
\hline BM-1 & Hallway outside room & 54 & 16.4 & 0.1735 \\
\hline BM-2 & Tile floor outside room & 60 & 18.2 & 0.1927 \\
\hline
\end{tabular}

TABLE 15: Lab B 2016 Site Survey Readings

\begin{tabular}{|c|l|c|c|c|}
\hline Location ID & Description & CPM & $\mu \mathrm{R} / \mathrm{hr}$ & $\mu \mathrm{Sv} / \mathrm{hr}$ \\
\hline SP-1 & Work Station adjacent to D8 & 41 & 12.4 & 0.1317 \\
\hline SP-2 & Work Station, D8 operator & 39 & 11.8 & 0.1253 \\
\hline SP-3 & Top left edge of sash & 18 & 5.5 & 0.0578 \\
\hline SP-4 & Bottom left edge of sash & 45 & 13.6 & 0.1445 \\
\hline SP-5 & Bottom left of instrument & 19 & 5.8 & 0.0610 \\
\hline SP-6 & Top left center of sash & 40 & 12.1 & 0.1285 \\
\hline SP-7 & Bottom left center of sash & 54 & 16.4 & 0.1735 \\
\hline SP-8 & Bottom left center of instrument & 26 & 7.9 & 0.0835 \\
\hline SP-9 & Top center of sash & 56 & 17.0 & 0.1799 \\
\hline SP-10 & Middle center of sash & 50 & 15.2 & 0.1606 \\
\hline SP-11 & Bottom center of sash & 51 & 15.5 & 0.1638 \\
\hline SP-12 & Bottom center of instrument & 31 & 9.4 & 0.0996 \\
\hline SP-13 & Middle left sash panel & 52 & 15.8 & 0.1670 \\
\hline SP-14 & Middle left center sash panel & 39 & 11.8 & 0.1253 \\
\hline SP-15 & Middle right center sash panel & 34 & 10.3 & 0.1092 \\
\hline SP-16 & Middle right sash panel & 71 & 21.5 & 0.2281 \\
\hline SP-17 & Top right center of sash & 39 & 11.8 & 0.1253 \\
\hline SP-18 & Bottom right center of sash & 20 & 6.1 & 0.0642 \\
\hline SP-19 & Bottom right center of instrument & 41 & 12.4 & 0.1317 \\
\hline SP-20 & Top right edge of sash & 26 & 7.9 & 0.0835 \\
\hline SP-21 & Bottom right edge of sash & 40 & 12.1 & 0.1285 \\
\hline SP-22 & Bottom right of instrument & 52 & 15.8 & 0.1670 \\
\hline SP-23 & Front of freeze dryer next to D8 & 47 & 14.2 & 0.1510 \\
\hline
\end{tabular}




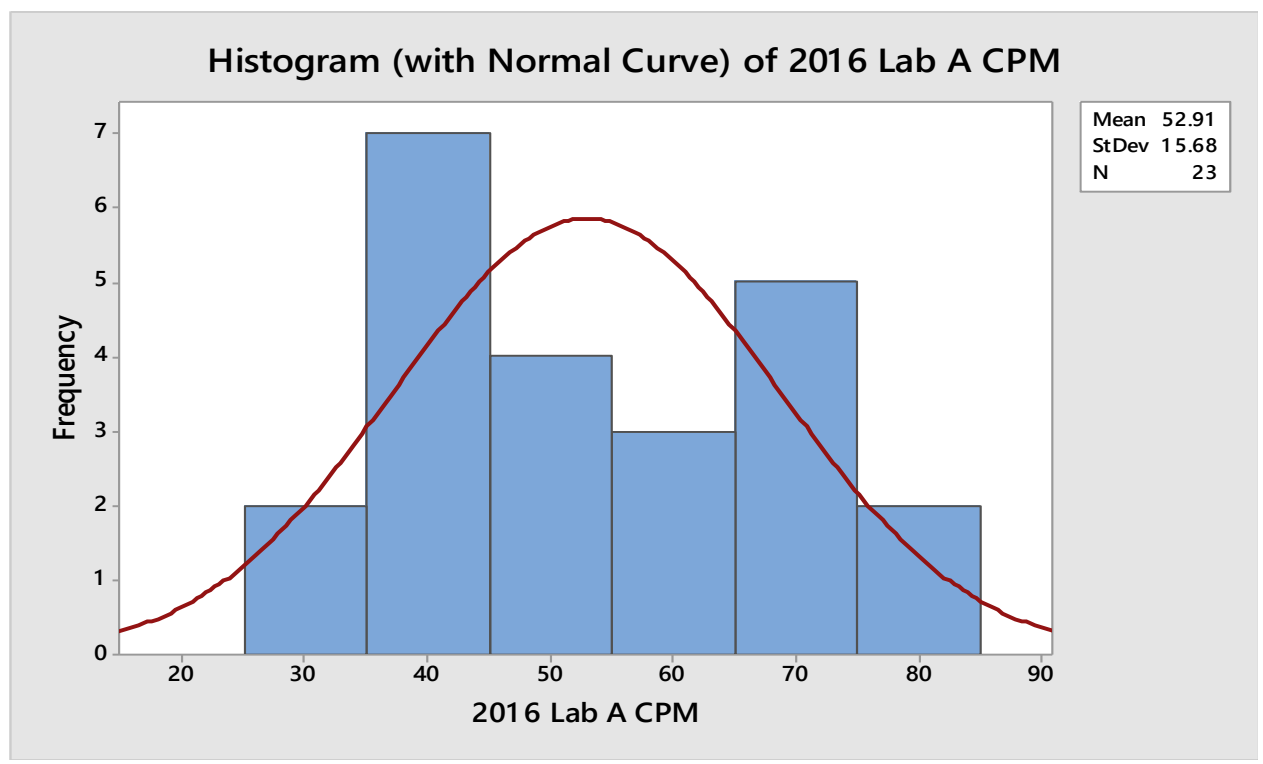

Figure 9: Lab A Histogram (CPM)

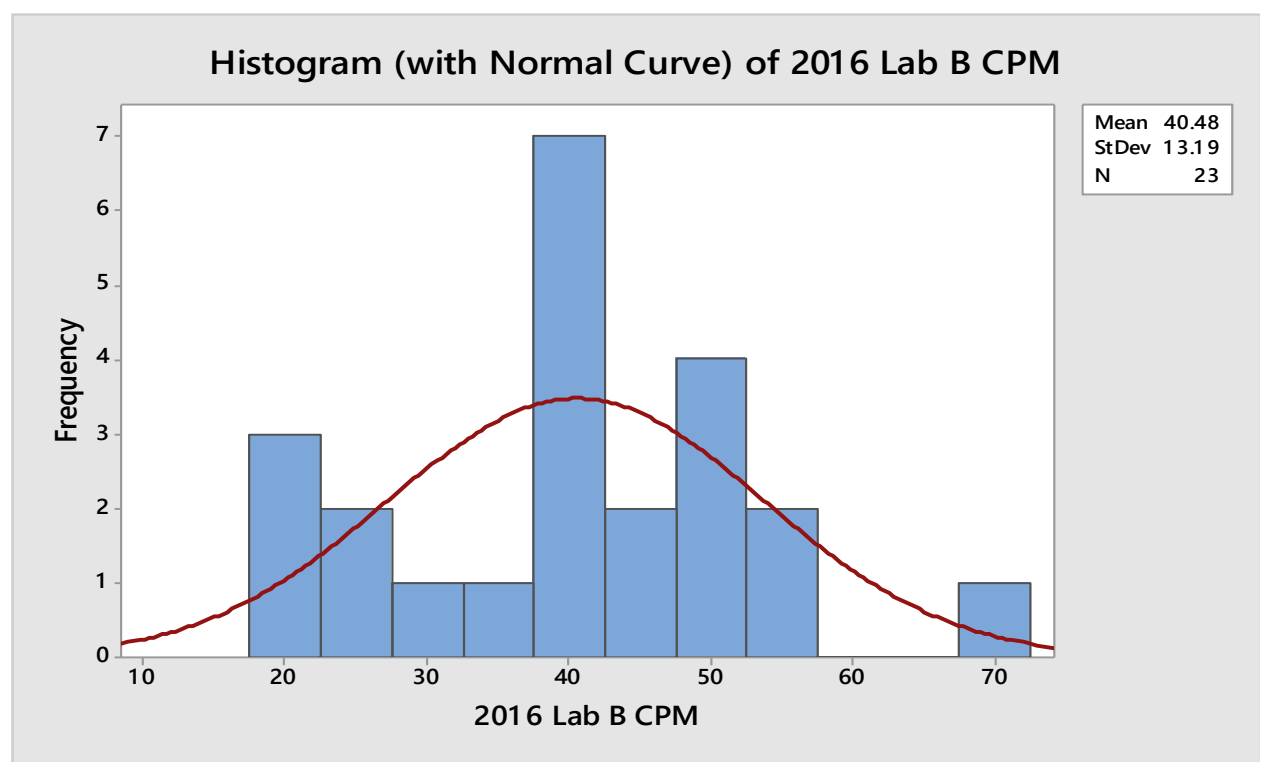

Figure 10: Lab B Histogram (CPM)

TABLE 16: Lab A and Lab B Descriptive Statistics (CPM)

\begin{tabular}{|c|c|c|c|c|c|c|c|c|}
\hline Variable & N & $\mathrm{N}^{*}$ & Mean & St. Dev. & Variance & Minimum & Median & Maximum \\
\hline 2016 Lab A CPM & 23 & 0 & 52.9 & 15.7 & 254.9 & 27.0 & 25.0 & 83.0 \\
\hline 2016 Lab B CPM & 23 & 0 & 40.5 & 13.2 & 174.1 & 18.0 & 40.0 & 71.0 \\
\hline
\end{tabular}




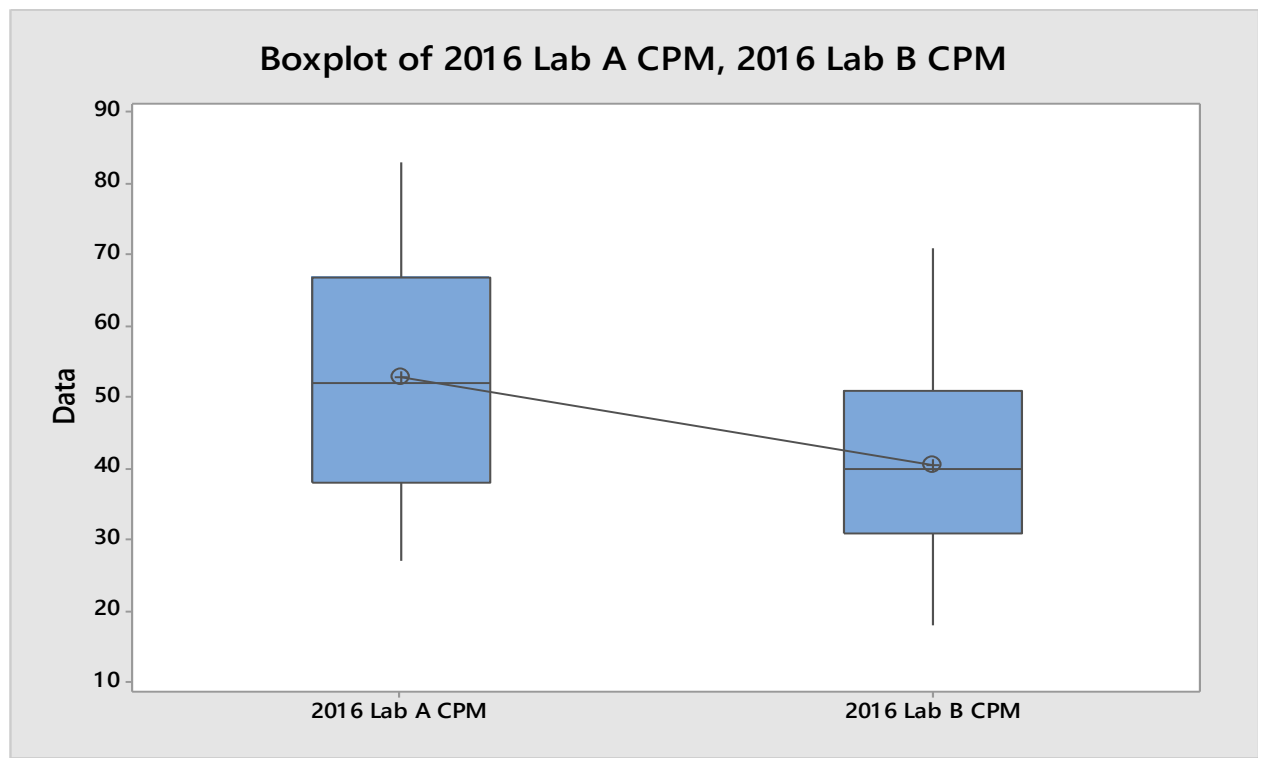

Figure 11: Box Plot of Two Sample T-test comparing Lab A and Lab B (CPM)

TABLE 17: Two-Sample T-Test and CI: 2016 Lab A and Lab B CPM

\begin{tabular}{|c|c|c|c|c|}
\hline \multicolumn{5}{|c|}{ Two-sample T for 2016 Lab A CPM vs 2016 Lab B CPM } \\
\hline & $\mathrm{N}$ & Mean & St. Dev. & SE Mean \\
\hline 2016 Lab A CPM & 23 & 52.9 & 15.7 & 3.3 \\
\hline 2016 Lab B CPM & 23 & 40.5 & 13.2 & 2.8 \\
\hline Difference $=\mu(2016$ Lab A CPM) - $\mu(2016$ Lab B CPM $)$ \\
Estimate for difference: 12.43 \\
95\% CI for difference: $(3.81,21.06)$ \\
T-Test of difference $=0$ (vs $\neq)$ : T-Value $=2.91$ P-Value $=0.006$ DF $=42$ \\
\hline
\end{tabular}




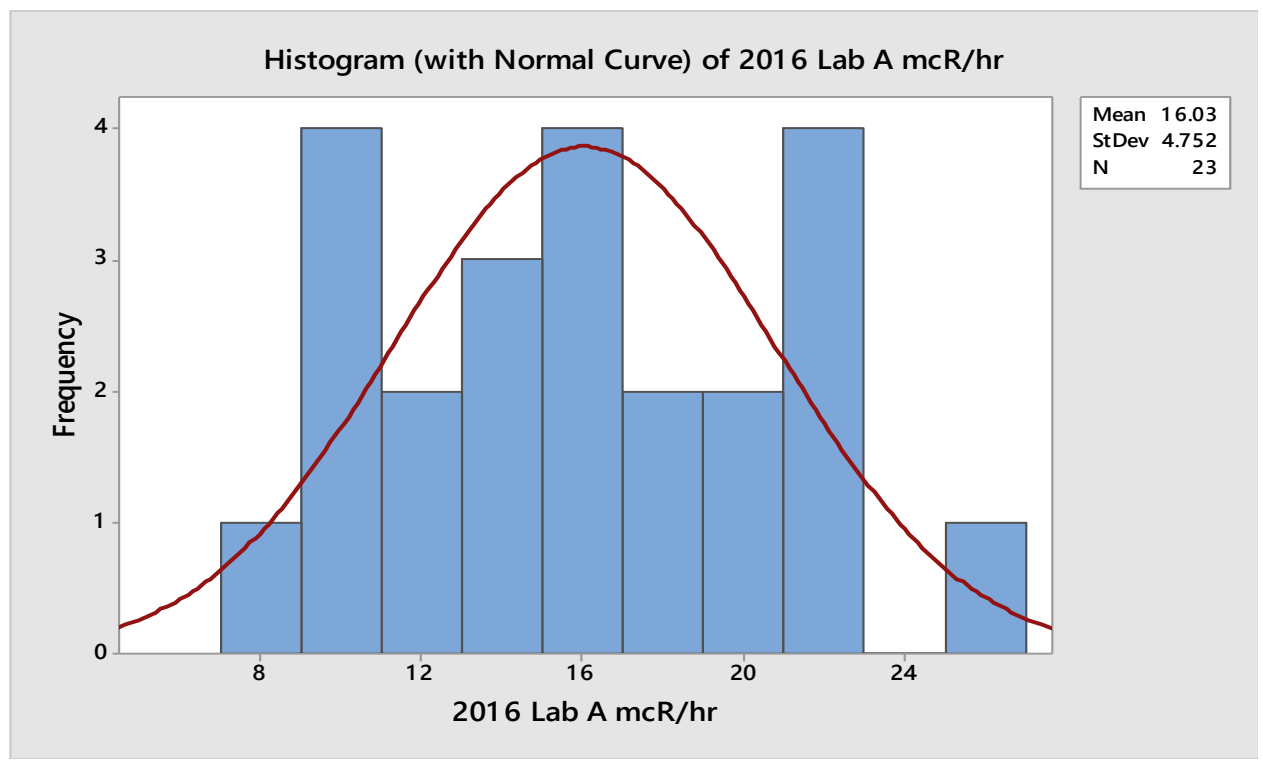

Figure 12: Lab A Histogram (mcR/hr)

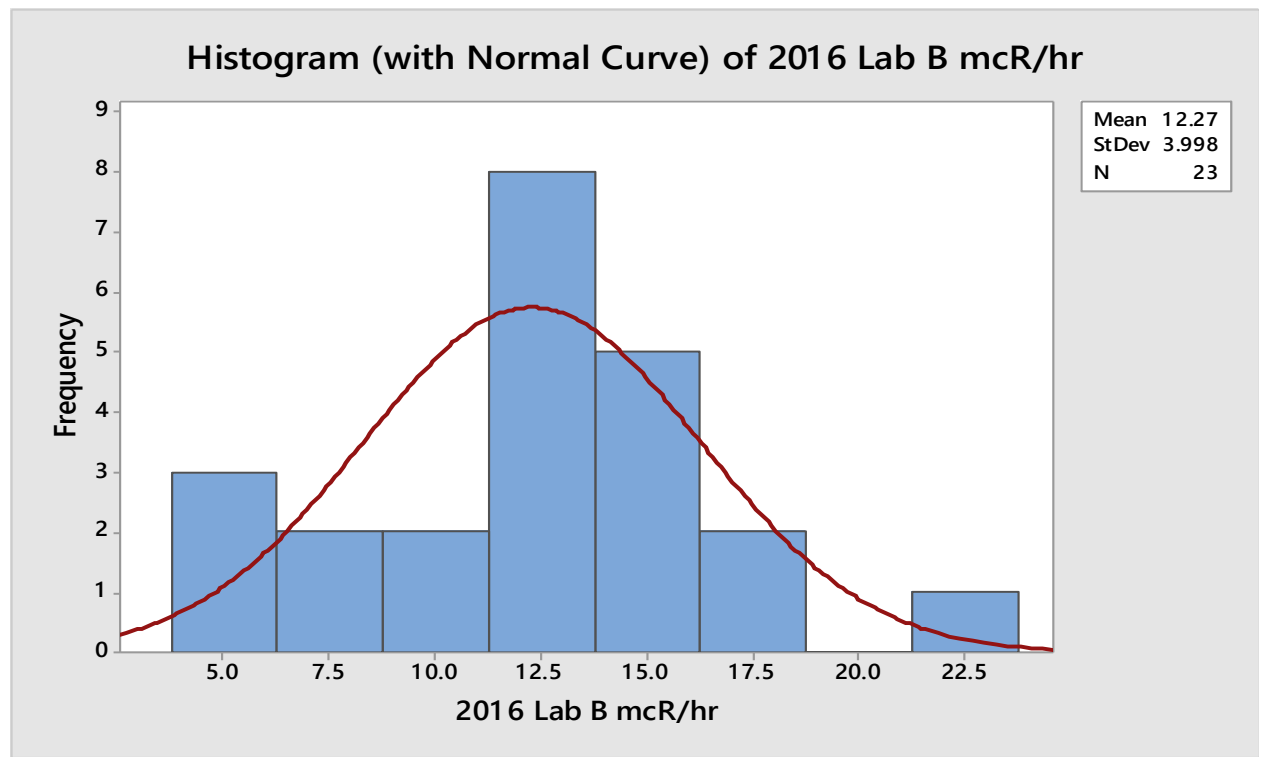

Figure 13: Lab B Histogram (mcR/hr)

TABLE 18: Lab A and Lab B Descriptive Statistics (mcR/hr)

\begin{tabular}{|c|c|c|c|c|c|c|c|c|}
\hline Variable & $\mathrm{N}$ & $\mathrm{N}^{*}$ & Mean & St. Dev. & Variance & Minimum & Median & Maximum \\
\hline 2016 Lab A mcR/hr & 23 & 0 & 16.0 & 4.8 & 22.6 & 8.2 & 15.8 & 25.2 \\
\hline 2016 Lab B mcR/hr & 23 & 0 & 12.3 & 4.0 & 16.0 & 5.5 & 12.1 & 21.5 \\
\hline
\end{tabular}




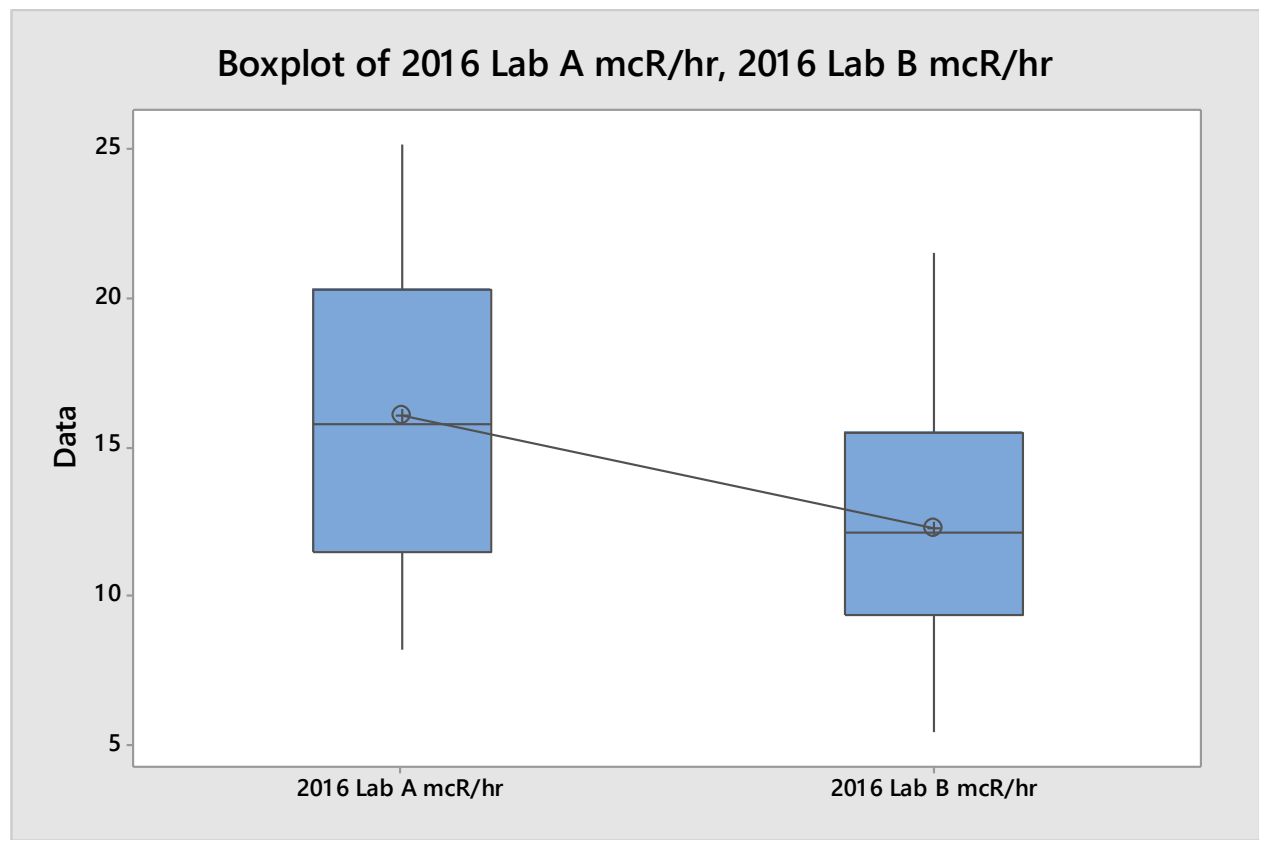

Figure 14: Box Plot of Two Sample T-test comparing Lab A and Lab B (mcR/hr)

TABLE 19: Two-Sample T-Test and CI: 2016 Lab A and Lab B mcR/hr,

\begin{tabular}{|c|c|c|c|c|}
\hline \multicolumn{5}{|c|}{ Two-sample T for 2016 Lab A mcR/hr vs 2016 Lab B mcR/hr } \\
\hline & $\mathrm{N}$ & Mean & St. Dev. & SE Mean \\
\hline 2016 Lab A CPM & 23 & 16.0 & 4.8 & 1.0 \\
\hline 2016 Lab B CPM & 23 & 12.3 & 4.0 & 0.8 \\
\hline \multicolumn{5}{|c|}{ Difference $=\mu(2016$ Lab A mcR/hr $)-\mu(2016 \mathrm{Lab} \mathrm{B} \mathrm{mcR/hr)}$} \\
Estimate for difference: 3.77 \\
95\% CI for difference: $(1.15,6.38)$ \\
T-Test of difference $=0($ vs $\neq):$ T-Value $=2.91$ P-Value $=0.006$ DF $=42$ \\
\hline
\end{tabular}




\section{One Way ANOVA for Lab A (3yr data)}

A One Way ANOVA for Lab A was conducted in order to complete a meta-analysis of 3yrs of historical data to analyze trends in the data.

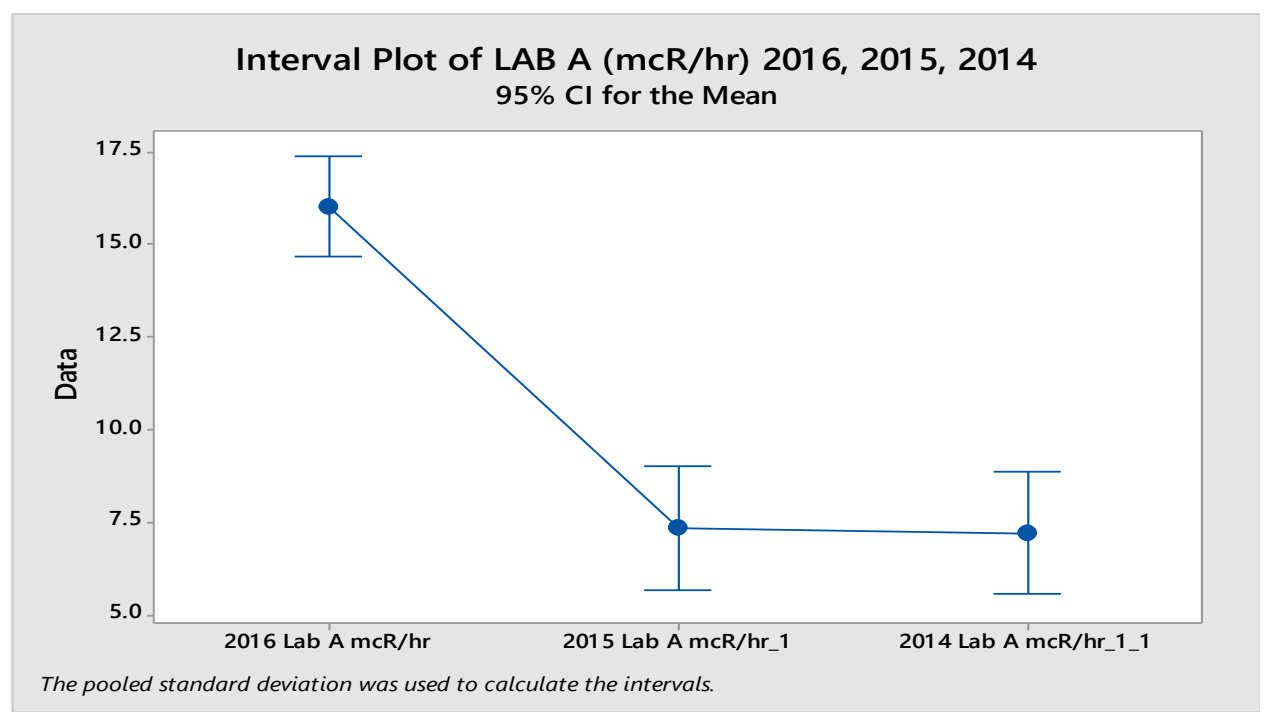

Figure 15: Interval Plot of Lab A (mcR/hr) 2016, 2015, 2014

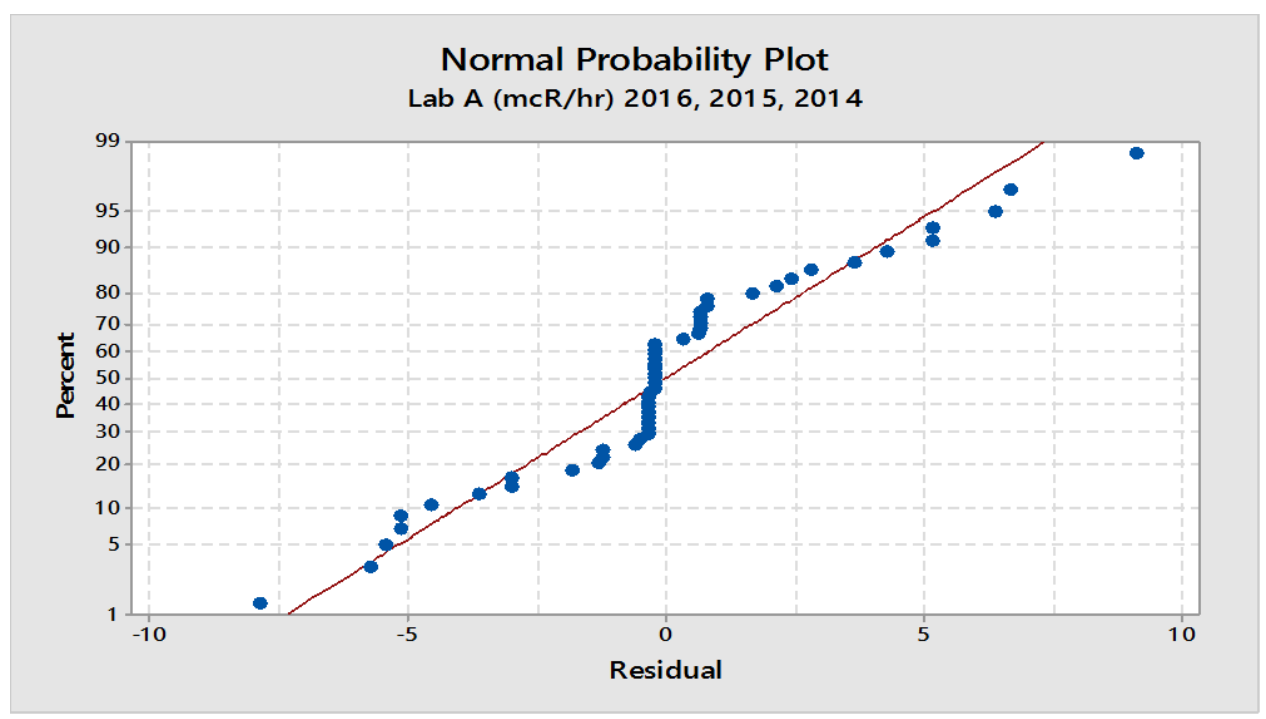

Figure 16: Normal Probability Plot Lab A (mcR/hr) 2016, 2015, 2014 
TABLE 20: One-Way ANOVA Lab A (mcR/hr) 2016, 2015, 2014 Statistical Summary

Method

Null hypothesis: All means are equal

Alternative hypothesis: At least one mean is different

Significance level $\quad \alpha=0.05$

Rows unused $\quad 16$

Equal variances were assumed for the analysis.

Factor Information

\begin{tabular}{|l|c|c|}
\hline Factor & Levels & Values \\
\hline Factor & 3 & 2016 Lab A mcR/hr, 2015 Lab A mcR/hr, 2014 Lab A mcR/hr \\
\hline
\end{tabular}

Analysis of Variance

\begin{tabular}{|l|c|c|c|c|c|}
\hline Source & DF & Adj SS & Adj MS & F-Value & P-Value \\
\hline Factor & 2 & 1002.4 & 501.2 & 48.5 & 0.0 \\
\hline Error & 50 & 516.7 & 10.3 & & \\
\hline Total & 52 & 1519.1 & & & \\
\hline
\end{tabular}

Model Summary

\begin{tabular}{|c|c|c|c|}
\hline S & R-sq & R-sq (adj) & R-sq (pred) \\
\hline 3.21 & $65.99 \%$ & $64.63 \%$ & $62.75 \%$ \\
\hline
\end{tabular}

\begin{tabular}{|l|c|c|c|c|}
\hline Means & N & Mean & St. Dev. & $95 \%$ CI \\
\hline Factor & 23 & 16.03 & 4.75 & $(14.69,17.38)$ \\
\hline 2016 Lab A mcR/hr & 15 & 7.32 & 0.73 & $(5.65,8.99)$ \\
\hline 2015 Lab A mcR/hr & 15 & 7.20 & 0.94 & $(5.53,8.87)$ \\
\hline 2014 Lab A mcR/hr & 3.21 \\
Pooled St. Dev. $=$ &
\end{tabular}




\section{One Way ANOVA for Lab B (3yr data)}

A One Way ANOVA for Lab B was conducted in order to complete a meta-analysis of 3 yrs of historical data to analyze trends in the data.

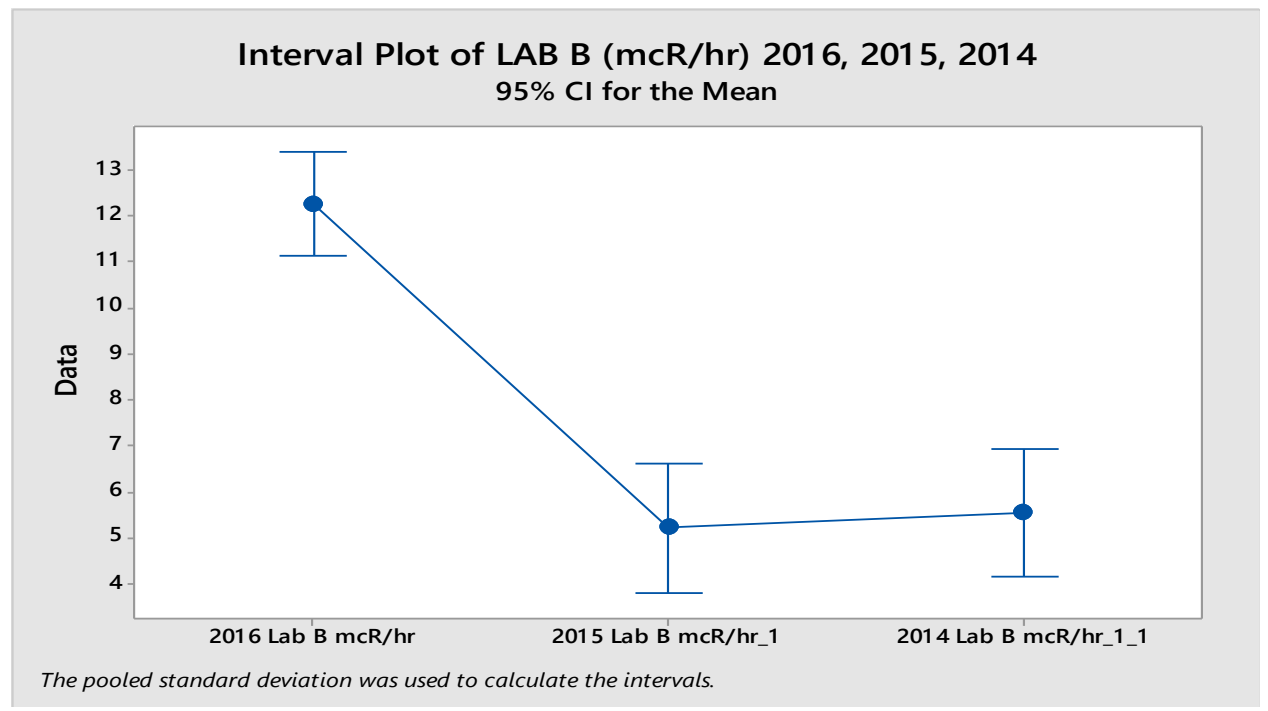

Figure 17: Interval Plot of Lab B (mcR/hr) 2016, 2015, 2014

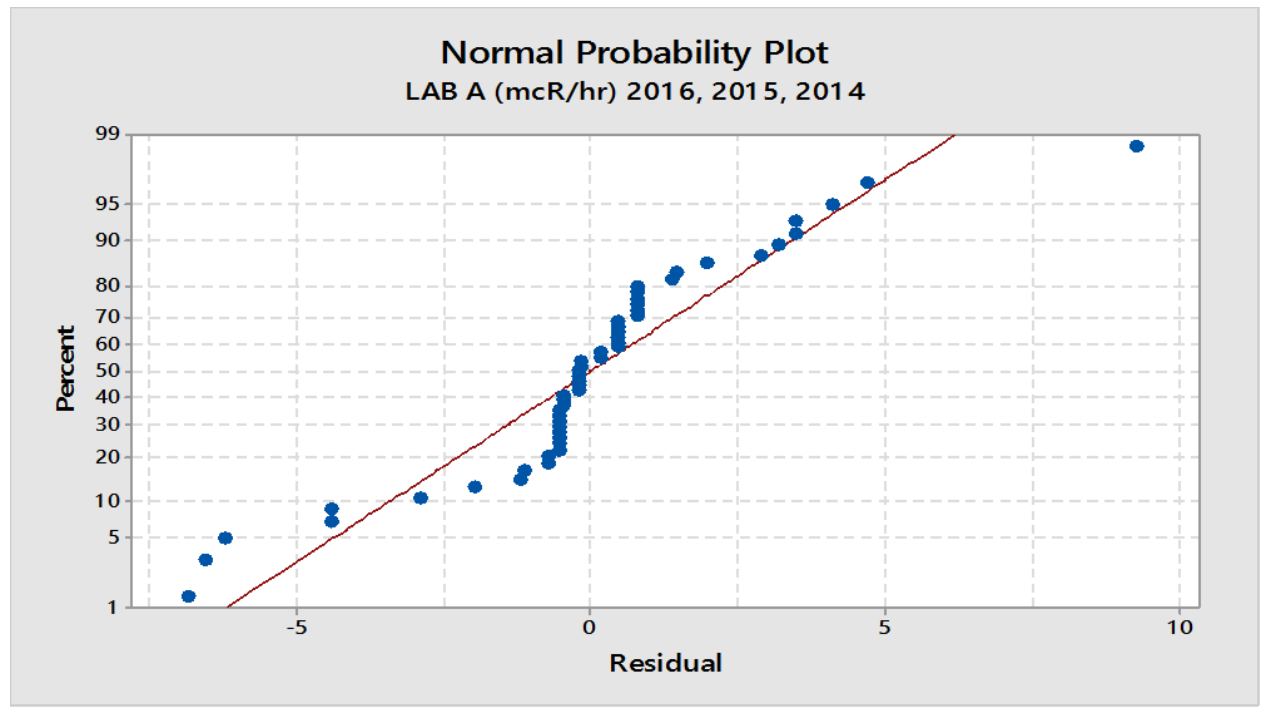

Figure 18: Normal Probability Plot Lab B (mcR/hr) 2016, 2015, 2014 
TABLE 21: One-Way ANOVA Lab B (mcR/hr) 2016, 2015, 2014 Statistical Summary

Method

Null hypothesis: All means are equal

Alternative hypothesis: At least one mean is different

Significance level $\quad \alpha=0.05$

Rows unused $\quad 16$

Equal variances were assumed for the analysis.

Factor Information

\begin{tabular}{|l|c|c|}
\hline Factor & Levels & Values \\
\hline Factor & 3 & 2016 Lab B mcR/hr, 2015 Lab B mcR/hr, 2014 Lab B mcR/hr \\
\hline
\end{tabular}

Analysis of Variance

\begin{tabular}{|l|c|c|c|c|c|}
\hline Source & DF & Adj SS & Adj MS & F-Value & P-Value \\
\hline Factor & 2 & 619.9 & 310.0 & 42.5 & 0.0 \\
\hline Error & 50 & 365.1 & 7.3 & \\
\hline Total & 52 & 985.0 & & \\
\hline
\end{tabular}

Model Summary

\begin{tabular}{|c|c|c|c|}
\hline S & R-sq & R-sq (adj) & R-sq (pred) \\
\hline 2.70 & $62.94 \%$ & $61.45 \%$ & $59.42 \%$ \\
\hline
\end{tabular}

\begin{tabular}{|l|c|c|c|c|}
\hline Means \\
\hline Factor & $\mathrm{N}$ & Mean & St. Dev. & $95 \%$ CI \\
\hline $2016 \mathrm{Lab} A \mathrm{mcR} / \mathrm{hr}$ & 23 & 12.27 & 4.00 & $(11.13,13.40)$ \\
\hline $2015 \mathrm{Lab} A \mathrm{mcR} / \mathrm{hr}$ & 15 & 5.21 & 0.74 & $(3.81,6.61)$ \\
\hline $2014 \mathrm{Lab}$ A mcR/hr & 15 & 5.53 & 0.64 & $(4.13,6.94)$ \\
\hline & & & \\
Pooled St. Dev. $=$ & 2.70 \\
\hline
\end{tabular}


Table 22: Lab A Annual Dose Exposure Summary

Annual Exposure $=8320 \mu \mathrm{R} / \mathrm{yr} \mathrm{X}(0.0106 \mu \mathrm{Sv} / \mathrm{hr} / 4 \mu \mathrm{R} / \mathrm{hr})$ $=8.82 \mathrm{E}-05$

Table 23: Lab B Annual Dose Exposure Summary

Exposure $=10608 \mu \mathrm{R} / \mathrm{yr} \mathrm{X}(0.0106 \mu \mathrm{Sv} / \mathrm{hr} / 5.1 \mu \mathrm{R} / \mathrm{hr})$ $=1.12 \mathrm{E}-04$ 


\section{CHAPTER 4: DISCUSSION}

The site survey for Lab A yielded an average reading of 52.9 CPM with ranges from $23-83$

CPM. The standard deviation was 15.7 with a variance of 245.9. The lowest background measurement was 70 CPM. Only one survey point was above the background level. (See Table 16)

The site survey for Lab B yielded an average reading of 40.5 CPM with ranges from $18-71$ CPM. The standard deviation was 13.2 with a variance of 174.1. The lowest background measurement was 54 CPM. Only one measurement was identified as being above the background. (See Table 16)

The two sample T-test displays a 95\% Confidence Interval for difference at 3.81 for Lab A and 21.06 for Lab B. The T-Value is 2.91 and the P-Value is 0.006. (See Table 17)

The site survey for Lab A yielded an average reading of $16 \mathrm{mcR} / \mathrm{hr}$ with ranges from $8.2-25.2$ $\mathrm{mcR} / \mathrm{hr}$. The standard deviation was 4.8 with a variance of 22.58 . The lowest background measurement was $21.2 \mathrm{mcR} / \mathrm{hr}$. Only one measurement was identified as being above the background. (See Table 18)

The site survey for Lab B yielded an average reading of $12.3 \mathrm{mcR} / \mathrm{hr}$ with ranges from $5.5-21.5$ $\mathrm{mcR} / \mathrm{hr}$. The standard deviation was 3.9 with a variance of 15.9. The lowest background measurement was $16.4 \mathrm{mcR} / \mathrm{hr}$. Only one measurement was identified as being above the background. (See Table 18)

The two sample T-test displays a 95\% Confidence Interval for difference at 1.15 for Lab A and 6.38 for Lab B. The T-Value is 2.91 and the P-Value is 0.006. (See Table 19)

The data for both the 2016 CPM and mcR/hr Lab A and B Survey Data indicates relatively tight data with low variability based on the standard deviations and variances for both labs. Histograms for these data sets show that neither survey appears to have a normal distribution curve, but Lab A has a better curve. The T and P-Values for the T-test indicate that the means are significantly statistically different. (See Tables 16-19 and Figures 9-14)

The one-way ANOVA for Lab A demonstrates a statistically significant difference between 2014, 2015, and 2016. 2014 and 2015 were much lower in comparison to the much higher 2016 
data. This was communicated through Figures 15-16 and Table 20. 2014 and 2015 were very similar, but 2016 shows a very large increase. As noted in the ANOVA plot above 2014 and 2015 were not significantly statistically different, however; both were highly significantly statistically different when compared to $2016(\mathrm{P}<0.05)$. The data also showed what appears to be grouping or the tendency to be bimodal. When looking at the normal probability plot, it appears to not be straight. "In general, this sort of curvature evinces bimodality." (Oswego, 2004) The ANOVA analysis clearly shows a large difference between 2016 and the subsequent years in terms of mean energy attenuation provided by the shielding. (See Table 20 and Figures 15-16)

The one-way ANOVA for Lab B demonstrates a statistically significant difference between 2014, 2015, and 2016 ( $\mathrm{P}<0.05)$. This was communicated through Figures 17-18 and Table 21. The survey means in 2014 and 2015 were much lower in comparison to the higher 2016 mean. In the same manner as Lab A, Lab B also reported higher than anticipated means for 2016. The normality of the analysis is once again worrisome, as the data appears to have no semblance of normality. The data indicates a change in 2016 from the previous 2 years (2014 and 2015) and three possibilities, listed previously, should be explored to find the cause of the difference in the data. (See Table 21 and Figures 17-18)

Three possible explanations, or a combination of explanations for this exists.

- The first is the power setting for which the Bruker unit is being used. The power range is adjustable from $20-60 \mathrm{kV}$ which would have an impact on the amount of radiation generated and emitted. The operator's manual states to start the machine on $40 \mathrm{kV}$. However, the power level has not been noted on any survey. Without knowing this, there is little confidence that the consistency has been maintained in regards to the power levels and could result in varying measurements.

- The second is related to the ceramic X-Ray tube which is needed to generate the radiation for diffractometry. The tubes for each unit were recently replaced. The age or hours of use were not noted for the older tubes. The new tubes could be generating more radiation than the older tubes. Future surveys will be able to assist in obtaining more historical data for degradation of the tubes. 
- The third explanation could be due to the type of survey equipment utilized. The 2016 survey was conducted using a Ludlum Gieger-Mueller Pancake Detector. This was used because it was the same equipment being used by the Certified Health Physicist from the consultant firm that conducted the state required survey. However, in reviewing the previous survey reports which were conducted by another consultant firm, it was noted that they used a Ludlum Sodium Ion (NaI) Gamma Scintillator detector as opposed to the Pancake detector. According to the manufacturer, the Gamma Scintillator better detects low-level gamma radiation. The manufacture lists the limit of detection for the Gamma Scintillator as nominally linear (within $10 \%$ ) from $5 \mu \mathrm{R} / \mathrm{hr}$ to $50 \mathrm{mR} / \mathrm{hr}$ whereas the Pancake detector has a limit of detection as nominally linear (within 10\%) from $1 \mathrm{mR} / \mathrm{hr}$ to $300 \mathrm{mR} / \mathrm{hr}$. In addition, the manufacturer states it is approximately 50 times more sensitive than the Pancake detector. Because both labs presented such low measurements, the Scintillator detector would have resulted in lower, more accurate readings. 


\section{CHAPTER 5: CONCLUSION}

Based on the data, there is a statistically significant difference between data observed in 2014 and 2015 for both labs when compared to the data from the 2016 survey. The 2016 data demonstrates higher measurements, but still below background radiation levels.

According to the survey results, both laboratories were near or below the background measurements with only one survey point above the background for each lab. As communicated in Table 22, the data for Lab A resulted in an annual exposure measurement of 8.82E-05 Sv/yr. As communicated in Table 23, the data for Lab B resulted in an annual exposure measurement of 1.12E-04 Sv/yr. Both of these are below the $0.05 \mathrm{~Sv} / \mathrm{yr}$ required by both Federal and State standards. Although Lab B had lower site survey measurements, it had a higher exposure measurement due to the larger difference between the survey measurements and the backgrounds 


\section{CHAPTER 6: RECOMMENDATIONS}

It is recommended that the company continue with the current established procedures. This includes continuing the current Preventative Maintenance Program, as well as replacing parts as needed. It should be noted that a new survey must be conducted any time a replacement part is installed on the unit, any changes occur in the operation, or the unit is moved to a new location. According to both standards identified in this report (64CRS23 and 10 CFR Part 20), personal dosimetry is not needed due to the low measurements, appropriate shielding, and the sealed source construction of the unit. If at any time a survey results in a level above the standard, additional testing must be conducted and personal dosimetry considered.

The final recommendation is to continue with the annual survey schedule conducted by or under the supervision of a Certified Health Physicist, with the following modifications to the survey:

- A request should be submitted to record the locations and values associated with all survey points. With this, more historical data can be obtained to see how levels fluctuate and where the strongest emissions occur.

- The power levels should be noted and kept consistent with each survey.

- A Scintillator detector should be used in future surveys to more accurately measure the lower level gamma radiation. 


\section{REFERENCES:}

Plog, B. A., \& Quinlan, P. J. (2002). Fundamentals of Industrial Hygiene (5th ed.). Itasca, IL: National Safety Council.

West Virginia Legislative Rule, Department of Health and Human Resources, Title 64 Series 23 (64CSR23) - Radiological Health Rules

U.S. Nuclear Regulatory Commission, Standard 10 CFR Part 20 - Standards for Protection Against Radiation

Bruker Technical Operations Manual. Madison, WI. BRUKER AXS, Inc. (2009)

Ludlum Model 2241-2RK Response Kit Technical Manual. Sweetwater, TX. Ludlum

Measurements, Inc. (2011)

\section{WEBSITES:}

Types of Ionizing Radiation. (2010, June 28). Retrieved from

https://www.mirion.com/introduction-to-radiation-safety/types-of-ionizing-radiation/

Four Primary Types of Ionizing Radiation. (2002, July 23). Retrieved from

www.umt.edu/media/research/eh/Materials/Radioactive/primarytypes.ppt

Normal Probability Plot. (2004, Fall). Retrieved from

https://oswego.edu/ srp/stats/normal_prb_plot.htm 


\section{APPENDIX}

\section{Appendix A: Certificate of Calibration}

\section{FA00440}

Certificate of Calibration

Atlantic Nuclear Corp. / 100 Weymouth St Unit E Rockland MA 02370

Tel (800) 878-9118 Fax (781) 878-3378

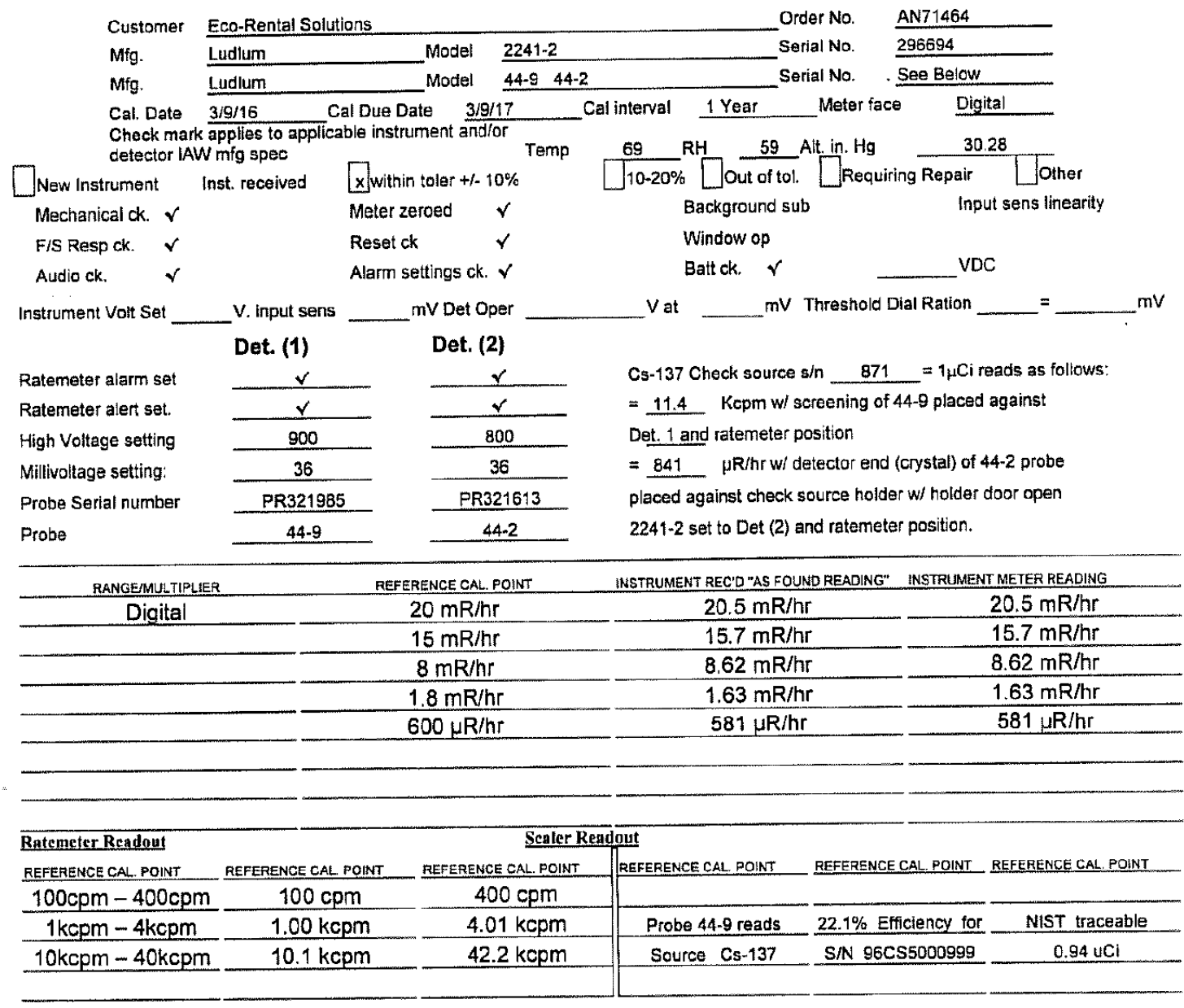

Reference Instruments and/or Sources: Cs-137 Gamma S/N

Alpha S/N

Beta $S / N$

X Other Cs-137 Range \& effic

区 $\mathrm{m} 500 \mathrm{~S} / \mathrm{N} \quad[4679 \quad$ DOscilloscope $\mathrm{S} / \mathrm{N}$

Multimeter $\mathrm{S} / \mathrm{N}$

Calibrated by:

Conthony Onguyen

Date:

$3 / 9 / 16$

All Calibrations are NIST traceable and compliant with ANSI/NCSL 2540-1-1994 and ANSI N323A-1997 with Attantic Nuclear

procedures unless otherwise stated. State of Massachusetts License number \# 56.0477 